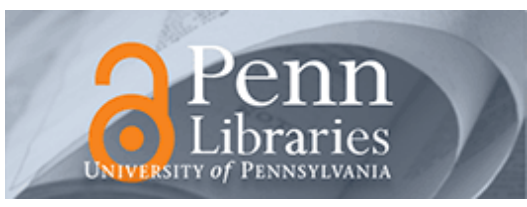

University of Pennsylvania ScholarlyCommons

Wharton Pension Research Council Working Papers

Wharton Pension Research Council

$2-1-2014$

\title{
Accounting and Actuarial Smoothing of Retirement Payouts in Participating Life Annuities
}

Raimond Maurer

Goethe University, maurer@finance.uni-frankfurt.de

Olivia S. Mitchell

The Wharton School, University of Pennsylvania, mitchelo@wharton.upenn.edu

Ralph Rogalla

Goethe University, rogalla@financie.uni-frankfurt.de

Ivonne Siegelin

Goethe University, ivonne.siegelin@hof.uni-frankfurt.de

Follow this and additional works at: https://repository.upenn.edu/prc_papers

Part of the Economics Commons

Maurer, Raimond; Mitchell, Olivia S.; Rogalla, Ralph; and Siegelin, Ivonne, "Accounting and Actuarial Smoothing of Retirement Payouts in Participating Life Annuities" (2014). Wharton Pension Research Council Working Papers. 85.

https://repository.upenn.edu/prc_papers/85

All opinions and any errors are solely those of the authors and not of the institutions with whom the authors are affiliated. (C) 2014 Maurer, Mitchell, Rogalla, and Siegelin.

This paper is posted at ScholarlyCommons. https://repository.upenn.edu/prc_papers/85

For more information, please contact repository@pobox.upenn.edu. 


\title{
Accounting and Actuarial Smoothing of Retirement Payouts in Participating Life Annuities
}

\begin{abstract}
Life insurers use accounting and actuarial techniques to smooth reporting of firm assets and liabilities, seeking to transfer surpluses in good years to cover benefit payouts in bad years. Yet these techniques been criticized as they make it difficult to assess insurers' true financial status. We develop stylized and realistically-calibrated models of participating lifetime annuities, an insurance product that pays retirees guaranteed lifelong benefits along with variable nonguaranteed surplus. Our goal is to illustrate how accounting and actuarial techniques for this product shape policyholder wellbeing as well as insurer profitability and stability. We show that smoothing adds value to both the annuitant and the insurer, so curtailing smoothing could undermine the market for long-term retirement payout products.
\end{abstract}

\section{Disciplines}

Economics

\section{Comments}

All opinions and any errors are solely those of the authors and not of the institutions with whom the authors are affiliated. (C) 2014 Maurer, Mitchell, Rogalla, and Siegelin. 


\title{
Accounting and Actuarial Smoothing of Retirement Payouts in Participating Life Annuities
}

\author{
Raimond Maurer, Olivia S. Mitchell, Ralph Rogalla, and Ivonne Siegelin
}

February 2014

\author{
PRC WP2014-02 \\ Pension Research Council Working Paper \\ Pension Research Council \\ The Wharton School, University of Pennsylvania \\ 3620 Locust Walk, 3000 SH-DH \\ Philadelphia, PA 19104-6302 \\ Tel: 215.898.7620 Fax: 215.573.3418 \\ Email: prc@wharton.upenn.edu \\ http://www.pensionresearchcouncil.org
}

The authors are grateful for research support provided by the TIAA-CREF Research Institute, the German Investment and Asset Management Association (BVI), the Pension Research Council/Boettner Center at The Wharton School of the University of Pennsylvania; and the Metzler Exchange Professor program. They also thank Benny Goodman and Michael Heller, and participants at Wharton's AEW Seminar, for comments. This research is part of the NBER programs on Aging, Public Economics, and Labor Studies. All opinions and any errors are solely those of the authors and not of the institutions with whom the authors are affiliated. (C) 2014 Maurer, Mitchell, Rogalla, and Siegelin.

All findings, interpretations, and conclusions of this paper represent the views of the authors and not those of the Wharton School or the Pension Research Council. (c) 2014 Pension Research Council of the Wharton School of the University of Pennsylvania. All rights reserved. 


\title{
Accounting and Actuarial Smoothing of Retirement Payouts in Participating Life Annuities
}

\begin{abstract}
$\underline{\text { Abstract }}$
Life insurers use accounting and actuarial techniques to smooth reporting of firm assets and liabilities, seeking to transfer surpluses in good years to cover benefit payouts in bad years. Yet these techniques been criticized as they make it difficult to assess insurers' true financial status. We develop stylized and realistically-calibrated models of participating lifetime annuities, an insurance product that pays retirees guaranteed lifelong benefits along with variable nonguaranteed surplus. Our goal is to illustrate how accounting and actuarial techniques for this product shape policyholder wellbeing as well as insurer profitability and stability. We show that smoothing adds value to both the annuitant and the insurer, so curtailing smoothing could undermine the market for long-term retirement payout products.
\end{abstract}

\section{Raimond Maurer}

Finance Department, Goethe University

Grueneburgplatz 1 (Uni-PF. H 23)

Frankfurt am Main, Germany

maurer@finance.uni-frankfurt.de

\section{Olivia Mitchell}

Wharton School, University of Pennsylvania

3620 Locust Walk, 3000 SH-DH

Philadelphia, PA 19104

mitchelo@wharton.upenn.edu

\section{Ralph Rogalla}

Finance Department, Goethe University

Grueneburgplatz 1 (Uni-PF. H 23)

Frankfurt am Main, Germany

rogalla@finance.uni-frankfurt.de

\author{
Ivonne Siegelin \\ Finance Department, Goethe University \\ Grueneburgplatz 1 (Uni-PF. H 23) \\ Frankfurt am Main, Germany \\ ivonne.siegelin@hof.uni-frankfurt.de
}




\section{Accounting and Actuarial Smoothing of Retirement Payouts in Participating Life Annuities}

Life is a short affair; we should try to make it smooth, and free from strife. Euripides

\section{Introduction}

Life insurers are permitted to employ both accounting rules and actuarial techniques to transfer surpluses earned in good years to support benefit payouts to policyholders in bad years. To this end, insurers have a long history of reporting asset values at historical costs rather than fair market values in their financial statements, and assessing their liabilities using an actuarial rather than an alternative approach. Yet such smoothing techniques have come under fire of late, in part due to life insurers' difficulties in the present low interest rate environment. Additionally, smoothing has been criticized for being nontransparent, making it difficult for shareholders, policyholders, and regulators to assess insurers' financial status (Jorgensen 2004). Moreover, based on their study of a Danish pension saving product, Guillen, Jorgensen, and Nielsen (2006) concluded that "smoothing is an illusion,” providing no value to policyholders. Their result, however, limited to a product that provided no payouts until maturity; that is, benefits depended on the contract's terminal value, but not on the particular return trajectory that led to this value.

This paper explores how these smoothing techniques affect participating payout life annuities (PLAs), an increasingly popular product intended for the retirement market in Europe and North America (Maurer, Rogalla, and Siegelin 2013). Also called with-profit annuities, PLAs provide retirees with a guaranteed benefit for life, along with variable non-guaranteed payments that depend on investment returns and mortality experiences of the insurance pool. Accordingly, the particular return trajectory has immediate consequences for the benefit stream provided by the annuity. Our goal is to examine how the smoothing techniques employed by actuaries and accountants shape the risk and return profiles of PLA payout streams, as well as insurer profitability and solvency.

Accounting smoothing in the insurance context values assets at historical cost rather than at fair market value; this practice helps shield insurer balance sheets and income statements against capital market volatility. Additionally, surpluses to be shared with policyholders are conventionally 
computed using realized gains and losses. By contrast, those pressing for fair market valuation of insurer assets seek to determine and distribute surpluses generated by unrealized as well as realized gains and losses. Of course this introduces additional volatility into the insurer's balance sheet, which could undermine insurer profitability and erase the appeal of retirement annuities. In addition to the accounting-related asset return smoothing, actuaries regularly smooth surplus payouts using a buffer fund on the liability side of the life insurer's balance sheet, known as the contingency reserve position.

For firms outside the insurance sector, international and general US accounting standards have moved from historical cost to fair market valuation, requiring that firms' financial statements report both liabilities and assets at market values. According to US Financial Accounting Standard FAS 157, fair market values are measured as quoted prices from orderly transactions of identical assets in active markets, or on a mark-to-model approach. ${ }^{1}$ When assets are recorded at fair market values, unrealized gains and losses influence company balance sheets and can also impact their income statements. FMV proponents contend that mark-to-market prices improve transparency since they reflect current market conditions, depict the true financial status of the insurer, and provide an effective early warning mechanism for investors, creditors, and regulators (Bleck and Liu 2007). This allows capital providers to evaluate the ex-ante risk and return profile of a potential investment in the firm and to monitor the use of its capital by managers ex post (c.f., Beyer, Cohen, Lys, and Walther 2010). Opponents argue that FMV can be misleading for assets held to maturity, may not be reliable if based on model prices, and could lead to undesirable firm actions. In the context of banks, Allen and Carletti (2008) and Sapra (2008) argue that mark-to-market valuation of illiquid assets can result in fire sales, downward spirals, as well as contagion between financial institutions in a financial crisis. Heaton, Lucas, and McDonald (2010) show, in a general equilibrium context, how mark-to-market accounting can negatively impact the real economy during a financial crisis. ${ }^{2}$

Despite the central importance of these actuarial and accounting rules for the life insurance industry, little has been written on the economic and financial impacts of these valuation approaches

\footnotetext{
${ }^{1}$ A similar definition is used according to International Accounting Standards (IAS).

2 Nevertheless Laux and Leuz (2010), using data on US banks, found no evidence that fair-value accounting created or exacerbated the severity of the 2008 financial crisis.
} 
on annuitants and the insurance companies offering these policies. In point of fact, smoothing permits losses to be deferred, but when assets must be sold to pay the benefits (and losses realized), this can trigger large reductions in benefit payments and challenge firm solvency. Smoothing also defers gains, and when the gains are realized, benefits can increase due to the larger value of the contingency reserve. To analyze these behaviors, we develop a model of a participating life annuity to show how using historical cost versus fair market valuation of assets can shape outcomes, as well as a contingency fund for liabilities can shape both policyholder wellbeing and insurer profitability. We illustrate how such actuarial and accounting techniques can be welfare-enhancing, in that riskaverse consumers may benefit substantially when insurers smooth asset and longevity surprises.

Our paper is related to the debate in the accounting literature about the pros and cons of fair market value accounting (FMA) versus historical cost accounting (HCA). In the U.S., most life insurance companies follow statutory accounting principles recommended by National Association of Insurance Commissioners (NAIC), which generally allow the recording of assets at historical costs. ${ }^{3}$ According to HCA, asset values are reported at purchase prices and updated later for amortization, but not for increases in market values (c.f., Laux and Leuz 2009, 2010). When market values decline, write-downs depend on how assets are classified in conjunction with an impairment test. For assets classified as "available for sale," write-downs are required, while those classified as "held-to maturity" are only written down when declines are perceived as non-temporary. There is some discretion for the company to classify assets across these categories. Exactly how these practices affect insurer behavior is, as yet, not well understood. Ellul et al. (2013) provide empirical evidence that HCA led US insurers to engage in strategic trading during the financial crisis, seeking to protect their solvency capital. ${ }^{4}$ And the Society of Actuaries (2013) recently noted that smoothing methods are important for "what financial results get disclosed in terms of funding rules, reported values and statutory reporting."5

\footnotetext{
${ }^{3}$ For a comprehensive discussion of accounting for insurance companies see, e.g., Herget et al. (2008) and Lombardi (2009).

${ }^{4}$ Specifically, they concluded that life insurers sought to shore up capital by selectively sells assets with high unrealized gains, whereas property and casualty firms did not.

${ }^{5}$ While not our primary focus here, in a related discussion various authors continue to debate what interest rate should be used to discount guaranteed annuity payments from pension plans (c.f., Hann, Heflin, and Subramanayam 2007, Comprix and Muller 2011, Jorgensen 2004, Novy-Marx and Rauh 2011).
} 
Our paper also builds on a growing literature regarding how households can use life annuities as retirement income instruments in a private accounts funded pension system. ${ }^{6}$ To date, however, these studies have focused mainly on the demand side, analyzing the welfare implications of having access to various types of life annuities and investigating when to optimally purchase life annuities. $^{7}$ Few have examined the relationship between accounting and actuarial policies, and insurer supply of these products. ${ }^{8}$ Moreover, most studies of household portfolio choice and annuitization have focused on fixed payout annuities, where the insurer takes on all capital market as well as mortality risk. A few studies have evaluated investment-linked/unit-linked annuities where the insurer passes on the investment risk to the policyholder, and also the longevity risk can be shared between the annuitant and the insurer. ${ }^{9}$ Most interesting is the case of participating annuities, which offer retirees access to the mortality credit as well as a smoothed payout stream over their remaining lifetimes.

In what follows, we provide a coherent analysis of PLAs from the perspective of the annuity purchaser and the insurer providing the annuity, and we examine how different accounting and actuarial rules influence results. Our goal is to show how these rules shape consumer utility and insurer profitability. To this end, we first discuss benefit smoothing within a stylized 2-period model. Subsequently, we develop a full-fledged, realistically calibrated stochastic asset-liability model of a life insurance company that offers a PLA, and we show how using historical cost versus fair market valuation of assets and maintaining a buffer fund influence both policyholder welfare and insurer profitability. The findings are likely to be of substantial interest to policymakers seeking to spur growth in the annuity market to enhance old-age security for those needing to manage their 401(k) plan drawdowns in retirement. ${ }^{10}$

\footnotetext{
${ }^{6}$ Work in the area includes Brown, Mitchell, Poterba, and Warshawsky (2001), Davidoff, Brown, and Diamond (2005), Milevsky and Young (2007), Horneff, Maurer, and Rogalla (2010).

${ }^{7}$ Other researchers seek to explain why households seem not to annuitize much; see Inkman, Lopez, and Michaelidis (2011).

${ }^{8}$ In a recent paper, Koijen and Yogo (2013) study the impact of financial and regulatory frictions on the supply side of life insurance.

${ }^{9}$ See Piggott, Valdez, and Detzel (2005), Denuit, Haberman, and Renshaw (2011), Richter and Weber (2011), Maurer, Mitchell, Rogalla, and Kartashov (2013).

${ }^{10}$ For instance Mark Iwry, senior adviser to the US Secretary of the Treasury and Deputy Assistant Secretary for retirement and health policy, has stated that "[o]ne solution is to provide for a predictable lifetime stream of income, such as an annuity provided under a retirement plan or IRA. By pooling those who live shorter and
} 


\section{A Stylized Model of Participating Life Annuity with Payout Smoothing}

\subsection{Setup}

To fix ideas, we first devise a simple 2-period model of a stylized PLA to illustrate the circumstances under which smoothing annuity payouts over time can increase annuitants' lifetime utility and add value to the insurer. The model setup is as follows: at time $t=0$, an individual purchases a PLA that, in the absence of payout smoothing, promises to pay the value of one fund unit (FU) at time $t=1$ and $t=2$, subject to the annuitant being alive. ${ }^{11}$ For notational convenience, we assume that the individual survives to $t=1$ with certainty and to $t=2$ with probability $p$. Under this assumption, and based on the actuarial equivalence principle, the premium charged by the insurer per PLA sold amounts to $(1+p) S_{0}$, where $S_{0}$ is the value of one FU at time $t=0$. On selling the PLA to $N$ annuitants, the insurer's initial reserves amount to $N \cdot(1+p)$ FUs. Due to benefit payouts, these reserves will decrease by $N$ FUs at time $t=1$, and by $N \cdot p$ FUs at time $t=$ 2, leaving the insurer with depleted reserves at the end of the model horizon. ${ }^{12}$

As time progresses, the FU value changes according to a binomial process: each period, it can either increase or decrease by a proportional factor $u$ or $d$. Consequently at time $t=1$, the FUs may be worth either $S_{u}=u \cdot S_{0}$ or $S_{d}=d \cdot S_{0}$, while at time $t=2$, their value may be $S_{u u}=$ $u^{2} \cdot S_{0}, S_{u d}=u d \cdot S_{0}, S_{d u}=d u \cdot S_{0}$, or $S_{d d}=d^{2} \cdot S_{0}$. Since PLA payouts are denominated in FUs, these price fluctuations (capital market movements) directly affect benefits paid to annuitants. By contrast, the insurer is not at risk because capital market risk is hedged by investing the collected premiums into the FUs underlying the PLA.

To mitigate the impact of FU price risk on annuity payouts, we now introduce a smoothing factor $y(\in[0 ; 1])$, representing the fraction of a FU that is deducted from (added to) the regular payout every time the FU value has increased (decreased) in the prior period. If, for example, the FU

longer than average, everybody can essentially put away what's necessary to reach the average life expectancy, and those who live longer than average will be protected.” (Steverman, 2012).

${ }^{11}$ Fund Units may represent a mutual fund or a single asset such as a stock. Hence, our model PLA can also be regarded as a unit-linked annuity. As we restrict our analysis to a 2-period model, we posit that the annuitant does not live to $t=3$.

12 This requires a sufficiently large number $N$ of annuitants, such that the insurer can perfectly eliminate individual longevity risks through pooling. Moreover, this requires that the survival probability $p$ is deterministic and known at time $t=0$. Hence, we abstract from systematic mortality risk. 
value increased to $S_{u}$ at $t=1$, the annuitant receives a payout of only $(1-y)$ FUs, worth $(1-y)$. $S_{u}$. If, on the other hand, the FU value decreased to $S_{d}$, the annuitant receives a payout of $(1+y)$ FUs, worth $(1+y) \cdot S_{d}$. Correspondingly, at time $=2$, if the FU value increases from $S_{u}$ to $S_{u u}$, the payout is $(1-y) S_{u u}$. Any FUs not paid out after a price increase are retained by the insurer, while the insurer must cover the additional payouts triggered by price drops. Figure 1 summarizes the alternative developments of the FU price and the corresponding evolution of annuity payouts and reserves held by the insurer after payouts are made.

\section{Figure 1 here}

This smoothing process reduces payout volatility, although it also reduces the expected benefit since the value of the FUs withheld in good states exceeds the value of the additional FUs received in bad states. From the annuitant's perspective, this may be appealing depending on the utility-maximizing smoothing factor $y$. Concurrently, the insurer's position is no longer risk-free. That is, in the absence of smoothing (i.e. $y=0$ ), the insurer's reserves are always depleted after the final annuity payouts have been made. With smoothing, however, the insurer will either have some FUs left or be some FUs short at time $t=2$, depending on how the capital market develops. Hence, from the perspective of the insurer, the question is whether the potential gains from retaining some FUs in up-states compensate sufficiently for the risk taken.

\subsection{Deriving the Optimal Smoothing Factor}

Next we take the annuitant's perspective and derive the smoothing factor $y$ that maximizes utility. To this end, we posit that the annuitant's preferences can be described by a time-separable constant relative risk aversion (CRRA) lifetime utility function defined over consumption:

$$
U_{0}=E_{0}^{\pi}\left[\beta \cdot \frac{C_{1}{ }^{1-\gamma}}{1-\gamma}+\beta^{2} \cdot p \cdot \frac{C_{2}^{1-\gamma}}{1-\gamma}\right]
$$

with consumption $C_{1}\left(C_{2}\right)$ at time $t=1(t=2)$ equal to the PLA payouts, a coefficient $\gamma$ of relative risk aversion, a time preference of $\beta$, and a probability of survival of $p$ to $t=2$. Here, $E_{0}^{\pi}$ is the expectation at time $t=0$ under the subjective probability measure $\pi$, with $\pi_{u}\left(\pi_{d}=1-\pi_{u}\right)$ representing the subjective probability for an increase (decrease) in FU prices. 
Substituting the PLA payout stream described in Figure 1 into the lifetime utility function and maximizing it with respect to the smoothing factor $y$, we get: ${ }^{13}$

$$
y=\frac{A^{\frac{1}{\gamma}}-B^{\frac{1}{\gamma}}}{A^{\frac{1}{\gamma}}+B^{\frac{1}{\gamma}}}
$$

with

$$
\begin{aligned}
& A=d^{1-\gamma} \cdot\left(\pi_{d}+\beta \cdot p\left(u^{1-\gamma} \cdot \pi_{u d}+d^{1-\gamma} \cdot \pi_{d}^{2}\right)\right) \\
& B=u^{1-\gamma} \cdot\left(\pi_{u}+\beta \cdot p\left(u^{1-\gamma} \cdot \pi_{u}^{2}+d^{1-\gamma} \cdot \pi_{d u}\right)\right) .
\end{aligned}
$$

If $A>B$, the smoothing factor $y$ is positive, i.e. smoothing will increase utility. For risk-averse investors with a typical coefficient of relative risk aversion of $\gamma>1$, smoothing will be appealing when the subjective probability for a market downturn $\left(\pi_{d}\right)$ and/or the volatility of FU prices (i.e. the difference between $u$ and $d$ ) are sufficiently high. In these situations, the potential utility loss from a capital market downturn cannot be compensated by the possible utility gain resulting from an increase in FU prices. Hence the annuitant will be willing to give up some upside potential as insurance against adverse capital market developments, as we will discuss more fully below.

Turning to the insurer's perspective, we next identify the smoothing factor that maximizes the value for the PLA provider. The insurer's gains/losses from smoothing PLA payouts depend on the number and value of the FUs remaining at time $t=2$ (see Figure 1). This payoff profile resembles a complex derivative strategy, a combination of two path-dependent options, which can be replicated by a dynamically rebalanced portfolio of the risky asset and (risk-free) cash. Consequently, it can be priced using risk-neutral valuation. Following this approach, it can easily be shown that the value $V I_{0}$ the insurer receives from payoff smoothing is given by:

$$
V I_{0}=\frac{N(1+p) S_{0} \cdot\left[q^{2} \cdot u^{2}-(1-q)^{2} \cdot d^{2}\right]}{(1+i)^{2}} \cdot y,
$$

with risk-free interest rate $i$ and a risk-neutral probability of an upward jump $q$. The value generated for the insurer is a linear function of the smoothing factor $y$; it is increasing in the smoothing factor

\footnotetext{
${ }^{13}$ See Appendix A for details.
} 
as long as the term in the squared brackets is positive. This is the case as long as the following relation between $u$ and $d$ holds: ${ }^{14}$

$$
\frac{(1+i) \cdot u}{2 u-(1+i)}>d
$$

The insurer profits from rising FU prices, since more valuable FUs will be retained. Hence the gains increase with the probability that FU prices increase. At the same time, higher FU price volatility (i.e. the difference between $u$ and $d$ ) will also increase the insurer's profit, inasmuch as the value of potential FU subsidies decreases when the value of potential FU withholdings increases.

In summary, this example shows that PLA payout smoothing adds value to both annuitant and insurer, as long as certain restrictions are met with respect to possible capital market developments, and as long as the annuitant believes that FU prices will drop with a particular probability.

\subsection{Numerical Example}

To provide additional insight into the conditions under which smoothing is beneficial, as well as the magnitude of the optimal smoothing factor, we next use reasonable calibrations for the parameters involved to evaluate analytical solutions for the framework just laid out. We assume that the annuitant has a time preference rate of $\beta=0.96$. The probability of survival to $t=2$ is set to $p=0.8$, which is approximately the 10-year survival probability of a US male aged 65 in 2013 . With respect to the capital market, we study two calibrations: a lower volatility regime with $u=1.2$, and a higher volatility regime with $u=1.3$ (in both cases $d=1 / u$ ). The first value corresponds to the development of annual total returns on the S\&P 500 over the period 1981 through 2012, while the second value focuses on the recent financial crisis and limits the calibration period to 2008 through 2012.

We seek to determine the subjective threshold probability of a market downturn $\pi_{d}^{*}$, beyond which smoothing will be beneficial for the annuitant. To find this threshold, we equate $A$ and $B$ in Equation (2b) and solve for the subjective probability. Figure 2 presents the results for a range of risk aversion values $\gamma$ and the two capital market specifications discussed above.

\footnotetext{
${ }^{14}$ Under the typical assumption $d=1 / u$, this inequality is always fulfilled (see Hull 2000, ch. 9.7, for details on how to calibrate a binomial model to historical data).
} 
Figure 2 here

As one would expect, the threshold probability is decreasing in the level of risk aversion. If payout smoothing is to increase utility, an annuitant with a low risk aversion of $\gamma=2$ must believe that markets will drop with a probability of around $40 \%$ or more. Conversely, a very risk averse annuitant with $\gamma=10$ benefits from smoothing even if he believes that there is a $95 \%$ probability that the markets will go up. With $\gamma=5$, our baseline calibration in subsequent analyses, the annuitant has a threshold probability of $\pi_{d}^{*}=18.9 \%(10.9 \%)$ in the low (high) volatility regime with $u=1.2(1.3)$.

Table 1 presents utility-maximizing smoothing factors $y$, the corresponding welfare gains for the annuitant, and the profits the insurer can generate by offering such a PLA. We show these for our two capital market calibrations for individuals with low, medium, and high risk aversion $(\gamma=$ 2,5 , and 10), and for two subjective probabilities of market downturns ( $\pi_{d}=0.2$ and 0.5$)$. These latter probabilities are derived by calibrating our binomial model to historical returns on the S\&P500, with the probability of $20 \%$ (50\%) corresponding to observations over the period 1981 (2008) through 2012.

Table 1 here

Results in Table 1 show that our baseline annuitant with medium risk aversion will optimally chose a PLA with a smoothing factor of $0.7 \%$, when he faces both low volatility and a low probability of a market downturn. This results in a small welfare gain of about one basis point, measured in terms of an increase in the certainty-equivalent fixed life annuity. An insurer offering such a PLA can generate a profit in the amount of $0.1 \%$ of the PLA premium. As indicated in Figure 2 , the subjective market downturn probability of $20 \%$ is only marginally above the threshold value beyond which smoothing is beneficial, which explains the modest amount of smoothing in this case. If, by contrast, the individual is exposed to a capital market having higher volatility and a higher (subjective) probability of a market downturn, he will elect a PLA with a much larger smoothing factor, $20.7 \%$. In other words, the annuitant would be willing to forfeit one-fifth of his benefit in good times, so as to have his payout increased by the same fraction when markets go down. Such a PLA generates a welfare gain of about $9.5 \%$ and a profit for the insurer of $2.7 \%$ of the annuity 
premium. Not surprisingly, in all scenarios, more risk averse individuals choose a higher level of smoothing. While the less risk averse do not demand smoothing in a normal capital market environment, in a high volatility scenario such as the present, they prefer a substantial smoothing factor of $13 \%$ for a welfare increase of 1.7 percent.

This simplified two-period model illustrates how PLA payout smoothing can be beneficial for both the annuitant and the insurer, where benefit payments are linked to the value of the underlying fund units meaning capital market risk is smoothed. Nevertheless we have not yet considered mortality risk, so next we turn to a more complete framework. This extends our model to incorporate mortality, and to generalize it to more periods and more assets. Most importantly, we allow two methods of smoothing using both actuarial and accounting techniques, and we examine their tradeoffs. To this we turn next.

\section{Analyzing a More Complex Participating Life Annuity Contract}

\subsection{Setup and Product Design}

To illustrate how payout smoothing works in a more realistic setting, we construct a model of a stylized life-insurance company that sells single premium participating life annuity contracts. In addition to realistic accounting and actuarial smoothing techniques, we incorporate capital market risk, and systematic as well as idiosyncratic mortality risk. Our stylized product model is closely modeled on the TIAA Traditional Annuity offered by the Teachers Insurance and Annuity Association-College Retirement Equities Fund (TIAA-CREF), one of the most important life insurance companies operating in the US market. ${ }^{15}$

The product we model is a participating life annuity (PLA) which provides retirees with lifetime guaranteed benefits plus non-guaranteed surplus payments. ${ }^{16}$ To price the guaranteed benefits, the company uses a specific mortality table in combination with an assumed interest rate to

\footnotetext{
15 In 2012, TIAA-CREF supervised 3.6 million annuity contracts and managed assets of \$487B. In the European market, participating life annuity products are offered comparable to the TIAA product outlined in the text; see Maurer, Rogalla, and Siegelin (2013) for a detailed discussion.

${ }^{16}$ The TIAA Traditional Annuity also builds up capital during the accumulation phase, whereby contributions paid by policyholders earn a minimum guaranteed yearly interest rate (depending on the vintage when premiums are paid) plus a non-guaranteed surplus. Here we concentrate only on the liquidation phase of the product.
} 
discount benefits (also called the guaranteed interest rate). The non-guaranteed surplus is determined annually by the insurer's Board of Trustees as a percentage of the guaranteed benefit and paid to annuitants the following year. The potential to generate surpluses stems from two sources: the insurer's experience on investment returns, and the realized annuitant pool mortality. When the return on the insurer's asset portfolio backing the liability due to promised annuity benefits exceeds the guaranteed interest rate, and/or if realized annuitant mortality is higher than expected, the insurance company earns a surplus. The company can influence the expected risk and return profile of uncertain surplus payments by its choice of assets in its portfolio. In addition, the insurance company can smooth the policyholder surpluses. To this end, accounting smoothing based on accounting standards, and actuarial smoothing based on building up reserves, both play central roles.

Accounting smoothing arises from the fact that unrealized gains and losses on assets are not used to calculate the investment return used to specify policyholder surpluses. In the U.S., most life insurance companies follow statutory accounting principles recommended by National Association of Insurance Commissioners (NAIC). These are specific accounting guidelines for insurers which permit the companies to value their bond portfolios in their annual statements using the historical cost approach. That is, these assets are recorded at their prices when purchased, and values are not updated for (non-credit related) changes in market values as long as they are unrealized. ${ }^{17}$

Actuarial smoothing results from withholding a part of the surplus earned in good years to support surplus payments in bad years. To this end, the insurer is permitted to build a special position on the liability side of its balance sheet, the so-called contingency reserve. Allocations into and withdrawals from the contingency reserve are governed by the insurer's Board of Trustees with guidance from the firm's actuaries.

In what follows, we introduce our realistically-calibrated company model for a pool of PLA policyholders with uncertain capital markets and mortality dynamics incorporating the above mentioned institutional features. Our goal is to spell out the implications of these various smoothing

\footnotetext{
${ }^{17}$ See Lombardi (2009) for further details on valuation requirements. Also, under NAIC rules, insurers may discount the liabilities resulting from the guaranteed benefit with a fixed interest rate specified at the beginning of the contract (i.e. the guaranteed interest rate). See for instance TIAA-CREF (2011).
} 
techniques from the perspective of the policyholder (i.e. the benefit stream) and the life insurance company (i.e., profitability and solvency), within such a realistic setting.

\subsection{The Insurance Provider}

We assume that the insurance company sells PLA contracts paying guaranteed lifetime benefits $G B$ to $I_{0}$ individuals of the same age $x$ (i.e. the pool is closed after the sale). The premium $P_{t}$ per contract paid at time $t$ is calculated according to:

$$
P_{t}=G B \cdot \sum_{k=0}^{\omega-(x+t)} \frac{{ }_{k} p_{x+t}^{A}}{(1+G I R)^{k}}
$$

Here ${ }_{k} p_{x}^{A}=\prod_{i=0}^{k-1}\left(1-q_{x+i}^{A}\right)$ is the $k$-period survival probability at age $x$, the $q_{x}^{A}$ are actuarial mortality rates used in the industry, and $\omega$ is the terminal age of the mortality table. GIR refers to the firm's guaranteed interest rate. ${ }^{18}$ To reflect the guaranteed annuity payment obligations, the insurance company builds a special reserve position on the liability side of its balance sheet, called the actuarial reserve. At time $t=0$, the actuarial reserve is equal to the total premium collected, i.e. $V_{0}=P_{0} \cdot I_{0}$. Multiplying the surviving number of annuitants $I_{t}$ by the present value of remaining benefits, given in equation (5), describes the evolution of the actuarial reserve in subsequent years, $V_{t}=P_{t} \cdot I_{t}$

The insurer invests the total premium collected into a portfolio of dividend-paying stocks and bonds paying coupons. This portfolio is recorded as the General Account on the asset side of the balance sheet of the insurance company, and at $t=0$, it is equal to the actuarial reserve. At the beginning of each subsequent year, the insurance company pays annuitant benefits from asset income (dividends/coupons) and from assets sold at market prices. The stochastic dynamics of the market prices of stocks are governed by a geometric random walk with drift and the evolution of bond prices is driven by a 3-Factor CIR term structure model (see Appendix B).

Depending on the insurer's investment and mortality experience, annuitants may receive surplus payments in addition to their guaranteed benefit. This surplus is generated when the insurer's total investment return exceeds the $G I R$, and/or when actual policyholder mortality exceeds that

\footnotetext{
${ }^{18}$ Here and throughout the analysis, we disregard explicit costs in terms of loadings, as these are not critical to our model.
} 
assumed when the annuity was price. The determination of the actual surplus generated by the insurer and, hence, the amounts paid out to annuitants, depend on a complex set of rules specified by the insurance company, to which we turn next.

The total annual surplus $T S_{t}$ generated by the insurer is given by:

$$
T S_{t}=M S_{t}+A S_{t}
$$

where the mortality surplus is $M S_{t}$ and $A S_{t}$ refers to the asset surplus. The mortality surplus arises from the difference between realized and anticipated mortality in the annuitant pool. Formally, the mortality surplus is calculated as:

$$
M S_{t}=V_{t+1} \cdot\left(\frac{I_{t}-I_{t+1}}{I_{t}}-q_{x+t}^{A}\right)
$$

where $V_{t}$ is the actuarial reserve for the surviving annuitants. $I_{t}$ represents the stochastic number of living annuitants at time $t$, is given by:

$$
I_{t}=\sum_{i=1}^{n} I_{t}^{i}
$$

Here, $I_{t}^{i}$ represents an indicator variable $I_{t}^{i}$ which takes the value of one if the annuitant $i(i=$ $1, \ldots, n ; n=I_{0}$ ) is alive at time $t$, and 0 if the annuitant has died. Over time, the sequence of indicator variables $I_{t}^{i}$ for each annuitant $i$ forms a Markov chain with:

$$
\begin{gathered}
P\left(I_{t+1}^{i}=1 \mid I_{t}^{i}=1\right)=1-q_{x+t}^{P}=p_{x+t}^{P}, \\
P\left(I_{t+1}^{i}=0 \mid I_{t}^{i}=1\right)=q_{x+t}^{P}, \\
P\left(I_{t+1}^{i}=0 \mid I_{t}^{i}=0\right)=1,
\end{gathered}
$$

where $q_{x+t}^{P}$ is the actual mortality rate of annuitants of age $x$ at time $t$. Actual mortality rates can differ from those used to price the PLA, as they are stochastic; their dynamics are modeled as in Cairns, Blake, and Dowd (2006) (see also Appendix B). Accordingly our model incorporates both idiosyncratic longevity risk (uncertainty about individual lifetimes), and also systematic longevity risk (uncertainty about the mortality table). 
The insurer's asset surplus naturally depends on the stochastic dynamics of the underlying stock/bond portfolio, and also on how the insurer values the assets. The relevant valuation method is determined by the accounting category into which each asset is classified. According to US Generally Accepted Accounting Principles, three asset categories are allowable: assets held to maturity, assets held for trading purposes, and assets available for sale (see e.g., Herget et al. 2008). Assets held to maturity are valued at amortized cost when acquired (historical cost valuation, or HCV); in this case, changes in asset prices are only recognized as gains or losses when the instruments are sold. Assets held for trading purposes are reported at fair market value (FMV), so price changes immediately affect the insurer's profits whether or not they are realized. ${ }^{19}$ Assets available for sale are also reported at FMV, yet unrealized gains and losses resulting from market price fluctuations are not stated in the insurer's profit and loss statement (P\&L). Instead, they are carried in a separate account on the liability side of the insurer's balance sheet, known as the Other Comprehensive Income account (OCI). When these assets are sold, the OCI account is reversed, and realized gains or losses are recorded in the P\&L.

Formally, when using FMV, the insurer's investment return on stocks, $i_{t}^{S, F M V}$ and on bonds, $i_{t}^{B, F M V}$, is given by:

$$
\begin{aligned}
i_{t}^{S, F M V} & =\frac{n_{S, t-1} \cdot\left(S_{t}-S_{t-1}\right)+n_{S, t} \cdot D_{t}}{\left(V_{t}-I_{t} \cdot L_{t}\right)} \\
i_{t}^{B, F M V} & =\frac{n_{B, t-1} \cdot\left(B_{t}-B_{t-1}\right)+n_{B, t} \cdot C_{t}}{\left(V_{t}-I_{t} \cdot L_{t}\right)}
\end{aligned}
$$

where $n_{B, t}\left(n_{S, t}\right)$ denotes the number of bond fund units (stocks) held in year $t ; B_{t}\left(S_{t}\right)$ refers to the price of the bond fund unit (stock) at time $t ; C_{t}\left(D_{t}\right)$ is the coupon (dividend) payment received on each bond fund unit (stock); and $L_{t}$ represents payments to individual annuitants. As indicated above, $V_{t}$ is the actuarial reserve, and $I_{t}$ is the number of policyholders in the pool.

Under the historical cost valuation method (or the other comprehensive income valuation approach), the corresponding returns $i_{t}^{S, H C V}$ and $i_{t}^{B, H C V}$ are calculated as:

\footnotetext{
${ }^{19}$ Under USGAAP, the default category of bonds (stocks) refers to those available for sale (held for trading) purposes. By contrast, under NAIC accounting, bonds are classified as held to maturity by default.
} 


$$
\begin{aligned}
i_{t}^{S, H C V} & =\frac{\left(n_{S, t-1}-n_{S, t}\right) \cdot\left(S_{t}-S_{0}\right)+n_{S, t} \cdot D_{t}}{\left(V_{t}-I_{t} \cdot L_{t}\right)} \\
i_{t}^{B, H C V} & =\frac{\left(n_{B, t-1}-n_{B, t}\right) \cdot\left(B_{t}-B_{0}\right)+n_{B, t} \cdot C_{t}}{\left(V_{t}-I_{t} \cdot L_{t}\right)}
\end{aligned}
$$

with $\left(n_{S, t-1}-n_{S, t}\right)$ the number of stocks sold, and $\left(n_{B, t-1}-n_{B, t}\right)$ the number of bond units sold. According to the OCI approach, unrealized gains and losses from price fluctuations are neutralized using the OCI account, which develops according to $O C I_{t}=O C I_{t-1}+n_{S, t-1} \cdot\left(S_{t}-S_{t-1}\right)+$ $n_{B, t-1} \cdot\left(B_{t}-B_{t-1}\right)$ where $O C I_{0}=0$. Therefore, investment returns are given by equations (11a) and (11b).

To some extent, life insurers may choose between the various valuation methods for their asset holdings. Naturally their choices have consequences for the asset surplus of the participating annuity. To study the impact of categorizing assets into different accounting valuation regimes, we define two parameters, $\alpha_{S}$ and $\alpha_{B}$, that specify the fraction of stocks and bonds valued using HCV (or OCI). Given those ratios and asset returns, the insurer's realized total investment return $i_{t}^{\text {TOTAL }}$ is calculated as:

$$
i_{t}^{\text {TOTAL }}=\left(1-\alpha_{S}\right) \cdot i_{t}^{S, F M V}+\alpha_{S} \cdot i_{t}^{S, H C V}+\left(1-\alpha_{B}\right) \cdot i_{t}^{B, F M V}+\alpha_{B} \cdot i_{t}^{B, H C V}
$$

Based on realized total investment returns, the firm's asset surplus for the pool is determined by:

$$
A S_{t}=\left(V_{t}-I_{t} \cdot L_{t}\right) \cdot\left(i_{t}^{T O T A L}-G I R\right)
$$

After the period's total surplus, $T S_{t}$, is determined, it must be distributed among annuitants and the insurer. To this end, we posit that the annuitants receive a fixed allocation percentage $a p$ subject to several constraints. Since the insurance company guarantees lifelong minimum benefits, policyholders do not participate in negative surpluses. Consequently negative surpluses directly decrease the insurer's equity capital. In addition, the level of surplus depends on the insurer's solvency capital, which includes three components: the insurer's equity capital, the value of its OCI account, and its contingency reserve. When the insurer's solvency capital exceeds a pre-specified solvency limit, an amount $a p \cdot T S_{t}$ is allocated to the policyholders; consequently, the insurance 
company keeps $(1-a p) \cdot T S_{t}$ of the surplus. When the insurer's solvency capital falls below the limit, we posit that $a p$ is reduced by $50 \%$, i.e. only $0.5 \cdot a p \cdot T S_{t}$ is allocated to the annuitants. The insurer thus retains the total surplus if no equity capital remains. ${ }^{20}$ Accordingly, the portion of total surplus allocated to policyholders, $D S_{t}$, is given by:

$$
D S_{t}= \begin{cases}\max \left(0 ; a p \cdot T S_{t}\right), & \text { if } E_{t}+O C I_{t}+C R_{t}>s l \cdot V_{t} \text { and } E_{t} \geq 0 \\ \max \left(0 ; 0.5 \cdot a p \cdot T S_{t}\right), & \text { if } E_{t}+O C I_{t}+C R_{t} \leq s l \cdot V_{t} \text { and } E_{t} \geq 0 \\ 0, & \text { if } E_{t}<0\end{cases}
$$

where $E_{t}$ is the insurer's equity, $O C I_{t}$ is the value of the OCI account, and $s l$ is the solvency limit, defined here as a fraction of the actuarial reserve. The surplus $D S_{t}$ is allocated to the contingency reserve $C R_{t}$.

Next, the insurance company must determine how much surplus to pay to the annuitants, defined as $P S_{t}$, and how much to retain in the contingency reserve. Typically this decision is made by the firm's Board of Trustees and informed by the insurer's chief actuary; the goal is to smooth annuitant payouts over time, given each year's realized surplus and the level of the contingency reserve. While the specifics of the decision process are not formally prescribed, we can characterize it using an algorithm which embodies both a backward- and a forward-looking component. By the backward-looking component, the current payout should be set in such a way that it is as similar as possible to the previous year's payout. The forward-looking element seeks to preserve this surplus stability in future years as well; this is implemented by maintaining a certain target level of the contingency reserve. To balance these two, the insurer will determine $P S_{t}$ such that the following objective function is maximized:

$$
\max _{P S_{t}} f\left(P S_{t}\right)+g\left(C R_{t}\right)
$$

where

\footnotetext{
${ }^{20}$ We posit that the annuity provider is part of an insurance group, so if the annuity provider's equity capital drops below zero, the parent company brings additional equity capital to pay guaranteed benefits. This precludes the need for us to take on the computational burden of modeling the consequences of formal insolvency.
} 


$$
\begin{gathered}
f\left(P S_{t}\right)=-\left(\frac{P S_{t}}{P S_{t-1}^{a d j}}-\frac{D S_{t}-P S_{t-1}^{a d j}}{P S_{t-1}^{a d j}}\right)^{2}+2\left(\frac{P S_{t}}{P S_{t-1}^{a d j}}-\frac{D S_{t}-P S_{t-1}^{a d j}}{P S_{t-1}^{a d j}}\right) \\
g\left(C R_{t}\right)=-\left(\frac{C R_{t}}{C R_{t}^{a i m}}\right)^{4}+4 \cdot\left(\frac{C R_{t}}{C R_{t}^{a i m}}\right)-2 \\
\frac{P S_{t}}{P S_{t-1}^{a d j}} \in\left[\frac{1}{b} ; b\right], b \geq 1 \\
C R_{t}=C R_{t-1}+D S_{t}-P S_{t}, C R_{t} \geq 0 \\
P S_{t-1}^{a d j}=P S_{t-1} \frac{I_{t}}{I_{t-1}}
\end{gathered}
$$

The objective function is concave and it has two terms, the polynomials $f$ and $g$. Both functions depend on the endogenous variable $P S_{t}$ and reach their maximum when the expressions within all parentheses are equal to one. Moreover, function $f$ depends on two components. The term $P S_{t} / P S_{t-1}^{a d j}$ seeks to keep annuitants' surplus payouts as close as possible to the previous period's level, where $P S_{t-1}^{a d j}$ is the previous period's surplus payout adjusted for the change in the size of the annuitant cohort $\left(I_{t} / I_{t-1}\right)$. The term $\left(D S_{t}-P S_{t-1}^{a d j}\right) / P S_{t-1}^{a d j}$ penalizes (rewards) the withholding of current realized surplus from annuitants when $D S_{t}$ is higher (lower) than $P S_{t-1}^{a d j}$. In other words, when the current surplus falls below (is above) last year's payout, the firm has an incentive to reduce (increase) payouts. To avoid extreme fluctuations in the surplus payouts, the surplus may vary only within a predefined boundary (equation 15d). For example, if $b=1.25$, the minimum (maximum) payout to each annuitant in the current year is $80 \%$ (125\%) of last year's payout.

Function $g$ is intended to sustain the insurer's ability to pay stable future surpluses. It reaches its maximum when the contingency reserve $C R_{t}$ equals the target value $C R_{t}^{\text {aim }}$, where the latter is a fraction of the current actuarial reserve. Inserting the transition equation (15e) into (15c) shows that the insurer withdraws from the contingency reserve when its previous level exceeds the target, i.e. $P S_{t}>D S_{t}$ if $C R_{t-1}>C R_{t}^{\text {aim }}$.

The interaction between the terms $f$ and $g$ reflects the tradeoff between paying policyholders more today, versus maintaining the insurer's stability for the future. In a period of high 
surplus, the $f$ function would call for increased benefit payments, but this will only be realized when the contingency reserve is high enough (according to the $g$ function). But if the contingency reserve is too low, the $g$ function inhibits the call for benefit increases. Conversely, in a period of low surplus, benefits would be reduced according to the $f$ function, unless a sufficiently high level of the contingency reserve encourages the insurer to maintain or even increase the benefit level.

Finally, the insurer's next year equity capital develops according to:

$$
E_{t+1}=\left\{\begin{array}{cl}
{\left[E_{t} \cdot(1+R(t, 1))+\left(T S_{t}-D S_{t}\right)\right] \cdot\left(1-\mu^{D}\right),} & \text { if } E_{t+1}+O C I_{t+1}+C R_{t}>s l \cdot V_{t+1} \\
E_{t} \cdot(1+R(t, 1))+\left(T S_{t}-D S_{t}\right), & \text { else }
\end{array}\right.
$$

where $R(t, 1)$ is the 1 -year government bond spot rate, and $\mu^{D}$ is the dividend rate paid to shareholders. The dividend is only paid if the insurer's next year solvency capital is adequate.

\subsection{The Policyholder}

To quantify how individuals with different risk aversion and time preferences value the stochastic PLA income stream, we use an expected utility framework as in Section 2. Specifically, policyholder preferences are modeled using a time additive constant relative risk aversion (CRRA) utility function as follows:

$$
U=E\left(\sum_{t=0}^{\omega-x} \beta^{t}{ }_{t} p_{x}^{P} \frac{L_{t}^{(1-\gamma)}}{1-\gamma}\right) .
$$

Here $\gamma$ denotes the consumer's coefficient of relative risk aversion and the discount factor $\beta<1$ represents the individual's subjective time preference. Following Maurer, Rogalla, and Siegelin (2013), the expected lifetime utility $U$ from the PLA benefit stream is transformed into a utilityequivalent fixed life annuity $E A$ :

$$
E A=\left[\frac{U(1-\gamma)}{\sum_{t=0}^{\omega-x} \beta^{t}{ }_{t} p_{x}^{P}}\right]^{\frac{1}{(1-\gamma)}} .
$$

The EA can be interpreted as the constant guaranteed lifetime income stream that the annuitant will require to give up the upside potential of a PLA with stochastic surpluses. 


\section{Numerical Evaluation}

\subsection{Setup and Calibration}

Next we describe the impact of actuarial and accounting smoothing on PLA policyholder utility and insurer profitability. We do so by simulating 5,000 independent sample paths of an insurer selling the PLA described above to a cohort of 10,000 males age 65 in 2013. Our goal is to compare the outcome for two cases: the first where surpluses are smoothed using the historical cost approach (accounting smoothing), and the second where assets are evaluating using historical costs and where actuarial reserves for liabilities are accumulated (accounting and actuarial smoothing).

We model a PLA paying a guaranteed lifetime benefit of $\$ 10,000$ per year. Premiums for guaranteed benefits as well as the actuarial reserve in later years are calculated using an interest rate of 3\% per year (similar to the TIAA Traditional Annuity), and the Annuity 2000 mortality table recommended by the Society of Actuaries with an age shift of four years. These assumptions imply a single premium per contract of $\$ 163,399$. In addition to the guaranteed benefits, the insurer promises to pay surpluses to the annuitants as described above. The surplus allocation parameter specifying how annuitants participate in total surpluses is assumed to be $a p=90 \%$. The surplus paid to policyholders in the first year is set to $2 \%$ of the guaranteed benefit. Also we assume that the company has equity capital worth $4 \%$ of the actuarial reserves, which we set as the solvency limit in equation (14). ${ }^{21}$

Next we describe the firm's initial balance sheet. The liability side includes the actuarial reserve, the contingency reserve, and the firm's equity capital. Without actuarial smoothing, the initial and targeted values of the contingency reserve are set to $0 \%$. With actuarial smoothing, the initial contingency reserve is set to $5 \%$ of the actuarial reserve and the target contingency reserve is set to $10 \%{ }^{22}$ Assets backing the actuarial reserve are held in the general account and invested in a constant-mix portfolio of stocks and bonds with a target duration of 10 years. The asset side also

\footnotetext{
${ }^{21}$ In doing so, we are informed by TIAA-CREF's 2011 financial statement which reported equity capital of $\$ 2 \mathrm{~B}$ and an actuarial reserve of $\$ 175 \mathrm{~B}$ (page 6). In addition TIAA-CREF reported valuation reserves (i.e. the difference between fair market minus book/adjusted carrying value), which increases the effective equity capital substantially. Since the initial valuation reserve in our model is zero, we adjust for this using a higher equity capital ratio.

${ }^{22}$ The TIAA-CREF 2011 financial statement reported a contingency reserve (\$23B) worth 13\% of the actuarial reserve (\$175B; page 6).
} 
includes a cash account corresponding to the contingency reserve and the insurer's equity capital. This earns an interest rate equal to the one-year spot rate given by the term structure model (see Appendix B).

Using our simulation results, we calculate the equivalent fixed life annuity (FLA) which would provide the same lifetime utility as the PLA. In our base case we stipulate a relative risk aversion of $\gamma=5$ and a time preference factor of $\beta=0.96$; these are subsequently varied in sensitivity analyses. The policyholder's subjective survival probabilities ${ }_{t} p_{x}^{P}$ are derived as in Appendix B. To explore the impact of actuarial and accounting techniques on annuitants' benefits and firm profitability, we permit the firm to select its asset allocation and choice of accounting method. To this end, we vary the asset allocation in the general account from all bonds to all stocks, and the valuation approach from all assets at historical cost (HCV Ratio $\alpha_{S}=\alpha_{B}=100 \%$ ), to all assets at fair market (HCV Ratio $\alpha_{S}=\alpha_{B}=0 \%$ ), all in $10 \%$ steps. In sensitivity analysis, we also allow for bonds to be valued according to the OCI instead of the HCV approach.

\subsection{The Annuitant's Perspective}

Figure 3 shows how alternative smoothing approaches influence annuitant wellbeing. Panel A involves only accounting smoothing but not actuarial smoothing; Panel B adds in actuarial smoothing. The graph on the left of each Panel depicts the benefit that a fixed life annuity (FLA) must pay so as to generate the same utility as the PLA with a guaranteed benefit of $\$ 10,000$ plus a variable surplus, for a range of asset allocations. The solid line reflects FLA values under HCV accounting, while the dotted line reflects the range of FLAs under fair market valuation. On the right, we illustrate the utility impact of permitting intermediate or blended accounting regimes, combining HCV and FMV in different proportions, again for a range of asset allocations.

Figure 3 here

Specifically, when the insurer invests only in bonds, the FLA is worth $8 \%$ more under full HCV accounting than under the FMV methord (\$12,300 vs. \$11,400; see Panel A1). Similar utility increases are observed for other asset allocations. In other words, if the only smoothing being undertaken is attributable to the accounting approach, historical cost valuation dominates fair market valuation from the annuitant's perspective. Moreover, utility rises as the fraction in bonds increases, 
but it turns down after about 70 percent. This holds regardless of the accounting rule: that is, diversification is beneficial, independent of the valuation approach selected.

In Panel A2, we see that the utility-equivalent FLA surface generally slopes upward as more assets are valued using the HCV approach, given a specific bond percentage. This is because using a higher HCV fraction lowers capital market volatility and thus generates a smoother surplus payout stream, which the policyholder prefers. Nevertheless, using only HCV is suboptimal because returns resulting from asset price appreciation are not immediately allocated to the surplus, which reduces the annuitant's payout. This is particularly relevant for stocks whose major source of return is asset price appreciation. Consequently, it is preferable to account for at least some of the portfolio using fair market valuation rules. For our base case with $\gamma=5$, the annuitant's optimal outcome would be for the insurer to hold 40 percent in bonds and use historical cost valuation for 80 percent of the assets, yielding a utility level equivalent to that of a fixed life annuity of almost $\$ 13,000$.

Panel B illustrates how the annuitant's perspective changes when the insurer can smooth using both accounting and actuarial methods. For a given portfolio allocation, Panel B1 shows that the utility equivalent outcomes are now more similar between the HCV and the FMV approaches. Compared to Panel A1, FMV plus actuarial smoothing results in utility increases of about 5\%, independent of asset allocation. This is because the actuarial smoothing dampens the surplus volatility introduced by FMV. By contrast, with the HCV approach, adding actuarial smoothing results in lower utility with an all-bond allocation by about $2 \%$, and by about $4 \%$ for an all-stock allocation. In other words, too much smoothing is not preferred by the PLA policyholder. Focusing last on the two curves in Panel B1, neither valuation regime clearly dominates. When the actuary removes substantial volatility via smoothing, the annuitant will prefer a higher stock fraction as compared to the case without actuarial smoothing.

As before, Panel B2 confirms that the utility-equivalent FLA surface rises as more assets are valued using the HCV approach, given a particular bond percentage. Yet the accounting regime now has less of an impact on utility levels than before. There is again an interior maximum to the surface: in our base case with $\gamma=5$, the annuitant would like the insurer to hold 60 percent in bonds and use historical cost valuation for 70 percent of the assets, yielding a utility level equivalent to that of a 
fixed life annuity of almost $\$ 12,300$. The higher fraction in bonds does curtail surplus volatility, but it also reduces earnings potential; moreover, actuarial smoothing shifts some of the surplus into the future, which is also detrimental to utility. The somewhat lower HCV fraction partly offsets these effects, but not by enough to generate utility comparable to that in Panel A2.

Table 2 also presents additional optimal utility equivalent FLAs for alternative values of risk aversion. We find the expected result, namely that when only accounting smoothing is available, the policyholder prefers both a higher bond fraction and a higher HCV ratio with increasing risk aversion. Including actuarial smoothing boosts the bond percent with no change in the HCV fraction, confirming our earlier finding that the valuation technique selected matters less in the case of actuarial smoothing. Finally, for all risk aversion values examined, when actuarial smoothing is in place, the policyholder can tolerate a higher share of assets valued at fair market.

Table 2 here

\subsection{The Insurer's Perspective}

Next we assess the insurer's perspective regarding asset valuation and smoothing methods. To this end, we calculate the internal rate of return (IRR) on capital provided by the insurer's shareholders for each simulation run. This computation accounts for the initial investment, along with periodic dividend payments. In addition, it includes what investors receive at the end of the product's lifespan, namely the value of equity capital, contingency reserve, and any actuarial reserves that remain when the last annuitant dies. We also consider the shortfall probability of the insurer, defined as the percent of times that equity capital is negative when the last policyholder dies. The time horizon for each simulation run varies depending on when the last annuitant is gone (a stochastic event).

Figure 4 plots the internal rate of return and shortfall probability as a function of the insurer's asset allocation and the accounting regime in place. Panel A presents results for the accounting smoothing alone, while Panel B reports findings where both the accounting and actuarial smoothing techniques are in force. For alternative asset allocations, Panel A1 plots the expected IRR for the two polar cases of the pure historical cost versus pure fair market accounting regimes. Clearly HCV dominates FMV in terms of IRR for all portfolio allocations. Additionally, the HCV produces 
positive expected IRRs in the range of 3-4 percent, whereas the FMV generates expected IRRs of -10 percent for an all-stock allocation, to -0.5 percent for an all-bond portfolio; the IRR is marginally positive in the middle-range bond allocation.

Figure 4 here

Panel A2 depicts how the expected internal return responds to alternative combinations of bonds and historical cost versus fair value accounting. Expected IRRs are increasing in the HCV ratio, a finding that holds for all asset allocation patterns. This occurs since unrealized surpluses must be paid out to the annuitants under FMV, while the insurer must bear unrealized losses which are not passed on to policyholders. By contrast, under HCV, unrealized losses from periods of bad performance are offset by unrealized surpluses from good performance, thus producing a smoothed impact on payouts. Such fluctuations reduce the value of the options held by annuitants. Moreover, IRRs are also generally rising with the percentage of the portfolio held in bonds, due to their more constant payment streams.

Finally, the shading in Figure 4 provides information about the insurer's shortfall probability, with darker areas representing more risk. Not surprisingly, holding an all-stock allocation along with the FMV approach is associated with a 20-25 percent shortfall probability; the insurer's equity capital would then be zero or negative. Moving toward a pure historical cost valuation, as well as to more bonds, substantially reduces the shortfall risk (to $0 \%$ ).

Panel A3 reports additional information about the development of the shortfall risk over time, illustrating the four cases of 100 percent bonds/all HCV, 100 percent stocks/all HCV, 100 percent bonds/all FMV, and 100 percent stocks/all FMV. Under both FMV scenarios, the insurer is exposed to substantial shortfall risk (over 30 percent) early in the retirement phase, which declines thereafter. Specifically, with the all-bond (all-stock) portfolio, the shortfall risk under fair market value falls after about year 2, and falls to about 5 (10) percent in the long term. Under the HCV/allbond allocation, there is no shortfall risk, whereas the HCV/all-stock combination provides an intermediate level (around 10 percent) of shortfall risk that peaks at 7-10 years and fades away thereafter. Also, under the HCV, an all-stock portfolio has the same shortfall risk as an all-bond portfolio under FMV. This underscores the strength of the smoothing approach under HCV: that is, 
in terms of shortfall risk, requiring an insurer to move from historical cost to fair market valuation has the same impact as requiring the insurer to hold only equity.

Turning to Panel B, where both accounting and actuarial smoothing are available, we note that the shapes of the expected IRR curves are similar to those presented in Panel A. Under the historical cost method depicted in Panel B1, expected returns are again positive for all portfolio allocations. By contrast, under FMV, the curve is more concave than before. The impact of adding actuarial smoothing is that funds must be set aside in a contingency reserve owned by the policyholders until the last annuitant dies; at that juncture, remaining assets are paid out to investors. This results in higher IRRs for the investor, as can be seen when the firm holds a high bond allocation.

Despite this general tendency, in the FMV scenario with actuarial intervention, the insurer holding all stocks receives a large negative expected IRR (-15 percent). With the actuary in place, by contrast, benefit payments are less directly linked to capital market performance; consequently, annuity payouts can be much higher than in the asset-smoothing only case. In particular, benefits are less likely to be reduced in bad times, which in turn diminishes investors' eventual claims. This is particularly likely when the portfolio allocation is heavy in stocks and it can offset the investor's opportunity to retain the contingency reserve.

Comparing Panels A2-B2 and A3-B3, we note that shortfall probabilities under the allstock/FMV scenario are even higher than without actuarial smoothing, and they do not decline as much with the passage of time. Thus with the all-stock portfolio, the shortfall risk under fair market value stands at about 17 percent in the long term, compared to 10 percent without actuarial smoothing. In other words, we conclude that under the historic cost approach, insurer stability and expected IRRs perform do better if the firm holds mostly bonds. That is, fair market valuation reduces stability and expected IRRs. Moreover, when the insurer holds mostly bonds, incorporating actuarial smoothing raises expected IRRs and offers some degree of protection for investors in terms of expected IRRs and shortfall risk.

To show that investors would find acceptable the utility-maximizing combinations of bond percentages and HCV ratios reported in Table 2, we summarize in Table 3 the corresponding 
expected IRRs, their volatilities, and shortfall probabilities. Overall, expected IRRs are moderately positive and shortfall probabilities are acceptably low. For example, given moderately risk-averse policyholders, accounting smoothing alone produces an expected IRR of 3.61 percent and shortfall probability of 1.58 percent; with actuarial smoothing, these values are 4.85 percent and 0.75 respectively. A similar pattern holds for other risk aversion patterns, except when very low risk aversion can produce a very high stock allocation.

Table 3 here

\subsection{Sensitivity Analysis}

To this point, we have modeled insurers as having the freedom to value their assets according to either HCF or FMV principles. In fact, however, regulators usually set standards for asset valuation practices. For example, the NAIC requires that bonds be valued according to the HCV approach by default, and stocks according to FMV. Accordingly, asset allocation will drive the insurer's valuation approach. Additionally, in addition to the HCF and FMV approaches, yet a different accounting valuation technique can also be used by life insurance companies if the latter issue securities on the stock exchange (as per the Securities and Exchange Commission). ${ }^{23}$ Known as the Other Comprehensive Income (OCI) approach, this is the default approach for bonds under US GAAP. ${ }^{24}$ Under OCI, assets are reported on the balance sheet using fair market valuation, while unrealized gains/losses are not reported on the P\&L statement but rather tracked in the OCI account.

Using the OCI approach produces identical investment returns as under HCM and hence the amount of surplus generated, but the two approaches differ with respect to the distribution of surpluses. This is because unrealized gains and losses recorded in the OCI account are part of the insurer's solvency capital, which influences the level of total surplus that can be allocated to policyholders according to equation (14). Thus, for instance, if the OCI account were sufficiently negative (positive), surplus distributions to annuitants could be reduced (increased). In what follows, we explore how our key results change when the insurer adopts OCI valuation instead of the alternatives.

\footnotetext{
${ }^{23}$ Specifically, the SEC seeks to insure that firm financial reports confirm to US GAAP so as to inform investors. By contrast, the purpose of the statutory accounting principles under NAIC guidelines is to protect insurer solvency.

${ }^{24}$ Stocks require fair market valuation.
} 
Figure 5 depicts how these alternative approaches influence both policyholder and insurer outcomes, with Panel A illustrating the impact of the accounting smoothing alone, while Panel B reflects what happens after adding actuarial smoothing. The three black lines (solid, dotted, and dashed) in the Figure illustrate what happens when all of the assets are evaluated according to a single valuation rule. The two red lines (solid and dashed) indicate results when stocks are valued at FMV, and bonds according either to HCM (the NAIC default) or OCI (the US GAAP default).

Figure 5 here

It is not surprising that the (red) utility-equivalent value curves of the affected annuity policyholder under the two mixture approaches lie between the two extremes previously discussed (Figure 3, Panel A1). When no actuarial smoothing is in effect, the fixed lifetime annuity (FLA) under OCI (dotted black line) is worth around 3\% more than with FMV, for the full range of portfolio allocations. Despite the fact that unrealized gains/losses do not directly affect surplus under OCI, losses do reduce the insurer's equity and through this channel may reduce the allocation of surplus to the annuitant. This explains why the utility-equivalent FLA is lower than under pure HCV (solid black line). If US GAAP defaults are in effect (dotted red line), stocks are fair market valued while bonds are valued using OCI. Consequently, at low bond allocations, US GAAP and FMV produce the same outcomes; by contrast, with high bond fractions, US GAAP valuations are similar to those with OCI. We observe similar results for NAIC valuation (solid red line): for a low bond allocation, results are similar to FMV, while at a high bond percent the pattern tracks that of the HCV approach. Under the NAIC approach (solid red line), results for low bond allocations are similar to the FMV outcome, but for higher allocations, the annuitant's utility equivalent is close to that under the HCV. Moreover, the NAIC technique provides more value to the annuitant than under the US GAAP methodology, because the former protects the policyholder from asset volatility with additional smoothing.

Turning to the insurer's perspective, Panel A2 makes clear that OCI (dashed black line) generates expected IRRs above those flowing from historical cost valuation (solid black line) for most portfolio allocations. This is because under OCI, as described above, even unrealized losses may reduce the surplus distributed and hence benefit payments. In turn, the investor retains more 
equity capital which reduces the need for shareholders to provide additional capital injections; this produces a higher expected IRR. By contrast, the insurer strongly disfavors the FMV approach (black dotted line), which produces negative expected returns across all portfolio allocations. For the US GAAP, the expected IRR curve (dashed red line) is a weighted average of the FMV and OCI approaches; for the NAIC curve (solid red line), the result is a weighted average of FMV and HCV. Overall, expected insurer profitability will be somewhat higher under US GAAP treatment compared to the NAIC approach, for realistic bond exposures. That is, there is a tension between the policyholder's preferred valuation method and that favored by the insurer.

Panel B indicates the impact of adding actuarial smoothing to the mix, and overall the results are quite similar. A comparison of Panels A1 and B1 shows that the additional smoothing provided by the actuary has relatively little impact on utility, for low equity exposures; if the insurer were to hold a riskier portfolio, the actuary's extra smoothing is slightly welfare-enhancing. Once again, annuitants see the NAIC technique as more appealing than US GAAP; actuarial smoothing has little marginal impact. Turning to the firm, a comparison of Panels B1 and B2 indicates that the expected IRR is higher with than without the actuary (for reasonable bond allocations ${ }^{25}$ ). Also, as before, insurer profitability is higher under US GAAP than NAIC for realistic bond exposures. Hence again there is a tension between the policyholder's preferred valuation method and that favored by the insurer.

Figure 6 illustrates how the key outcomes depend as a function of surplus fraction attributed to annuitants $(a p)$. All results are based on the asset allocation and book value ratio that maximizes the annuitant's utility. The solid line depicts utility-equivalent FLA values (left axis), while the dashed line (right axis) illustrates expected IRRs, as we vary ap from 0.8 to 1.0 (around the 0.9 base case above). First, and somewhat surprisingly, annuitant values are relatively insensitive to variations in ap. The reason is that attributing high values of the surplus to annuitants leaves the insurer unduly exposed to capital market shocks; this in turn increases the chance that surplus allocations will be cut to avoid insolvency, in which case the annuitants may end up with lower benefits. Second, the

\footnotetext{
${ }^{25}$ For example, TIAA-CREF (2011, page 6) holds about $85 \%$ of its assets in fixed income calculated as follows: bonds (\$168B) plus mortgages and contract loans $(\$ 14.5 \mathrm{~B})$ plus cash $(\$ 0.6 \mathrm{~B})$ divided by total admitted assets (\$226B) less separate account assets (\$16B).
} 
insurer's expected IRR is much more responsive, dropping from 6 to 1.5 percent, as the portion of surplus dedicated to the annuitant rises. In other words, for reasonable sharing rates and assuming actuarial intervention, smoothing using mostly historical cost valuation is preferable to fair market valuation. $^{26}$

Figure 6 here

To summarize, this section confirms that accounting smoothing is appealing to the annuitant and, for reasonable bond allocations, to the insurer as well. The insurer finds attractive high bond exposures along with historical cost value accounting, as this combination helps stabilize returns and reduce the cost of the guarantee issued to policyholders. Such a conservative investment and valuation approach is also congruent with policyholder preferences, since annuitants favor stable payout profiles. Adding actuarial smoothing techniques improves the insurer's profitability and solvency situation, given a realistic bond fraction and FMV accounting. Yet an approach that stresses more fair market valuation such as OCI will be unattractive to the annuitant.

\section{Conclusions}

A participating payout annuity can be a very attractive mechanism to provide retirees a guaranteed benefit plus some upside potential in the form of surplus sharing, while handling systematic shocks to mortality tables, capital market uncertainty, and default risk. Our paper develops a realistically-calibrated model of such a product to investigate how alternative accounting and actuarial valuation techniques can influence policyholder welfare as well as insurer profitability and stability. Our main contribution is to study how two different smoothing mechanisms shape policyholder and insurer outcomes, to help illuminate the current public debate about whether to push insurance companies to undertake fair market valuation. We show that smoothing reduces volatility without subtracting the expected returns from holding equity; consequently, smoothing is economically attractive to risk-averse annuitants and affordable for insurers. In this sense, smoothing is not simply an illusion in the insurance context.

\footnotetext{
${ }^{26}$ In results not detailed here, we also conclude that the preferred bond fraction is in the range of 0.6-0.7.
} 
Using a simple two-period illustrative model, we showed how PLA payout smoothing can add value to both annuitant and insurer. Next, a more complex approach examined how insurers can use accounting and actuarial techniques to smooth reporting with the goal of transferring surpluses earned in good years to support benefit payouts in bad years. Nevertheless with such smoothing, investors and policyholders are hard-pressed to perceive an insurer's true financial status. Accordingly, the practice has prompted calls for fair market valuation in insurance company's balance sheets. Yet this also introduces additional volatility which could undermine insurer profitability and the appeal of retirement annuities.

Our findings should be of considerable current interest, since insurance company valuation techniques have been charged in the press with being nontransparent and potentially conducive to insurer instability. Moreover, international accounting standards are moving away from historical cost accounting toward a fair value approach, requiring that companies report both liabilities and assets at market values. While this movement will enhance reporting to those seeking to buy insurance company shares, curtailing smoothing also threatens policyholders seeking the protection associated with long-term PLA retirement products. 


\section{Appendix A: Proof of Equations (2) and (3)}

The CRRA lifetime utility function describing the annuitant's preferences is given by

$$
U_{0}=E_{0}^{\pi}\left[\beta \cdot \frac{C_{1}{ }^{1-\gamma}}{1-\gamma}+\beta^{2} \cdot p \frac{C_{2}^{1-\gamma}}{1-\gamma}\right] .
$$

where the coefficient of relative risk aversion is $\gamma$, the rate of time preference is $\beta$, the probability of survival to $t=2(t=1)$ of $p(1)$, and the expectation $E_{0}^{\pi}$ at time $t=0$ under the subjective probability measure $\pi$. The realization and the probability of the consumption $C_{1}\left(C_{2}\right)$ at time $t=1$ $(t=2)$ are as follows:

$C_{1}=\left\{\begin{array}{ccc}(1-y) \cdot u S_{0} & \text { with probability } & \pi_{u} \\ (1+y) \cdot d S_{0} & \text { with probability } & \pi_{d}=1-\pi_{u}\end{array} \quad\right.$ and

$C_{2}=\left\{\begin{array}{llc}(1-y) \cdot u^{2} S_{0} & \text { with probability } & \pi_{u}^{2} \\ (1+y) \cdot u d S_{0} & \text { with probability } & \pi_{u d} \\ (1-y) \cdot d u S_{0} & \text { with probability } & \pi_{d u} \\ (1+y) \cdot d^{2} S_{0} & \text { with probability } & \pi_{d}^{2}\end{array}\right.$

where $\pi_{u}\left(\pi_{d}=1-\pi_{u}\right)$ measures the subjective probability for an increase (decrease). Next we factor out $\beta /(1-\gamma)$ and replace the expected consumption by its realization and probability:

$$
\begin{aligned}
U_{0}=\frac{\beta}{1-\gamma}\{[ & {\left.[1-y) u S_{0}\right]^{1-\gamma} \cdot \pi_{u}+\left[(1+y) d S_{0}\right]^{1-\gamma} \cdot \pi_{d}+\beta p\left(\left[(1-y) u^{2} S_{0}\right]^{1-\gamma} \cdot \pi_{u}^{2}\right.} \\
& \left.\left.+\left[(1+y) u d S_{0}\right]^{1-\gamma} \cdot \pi_{u d}+\left[(1-y) d u S_{0}\right]^{1-\gamma} \cdot \pi_{d u}+\left[(1+y) d^{2} S_{0}\right]^{1-\gamma} \cdot \pi_{d}^{2}\right)\right\}
\end{aligned}
$$

Rearranging terms we get:

$$
\begin{array}{r}
U_{0}=\frac{\beta}{1-\gamma} \cdot S_{0}{ }^{1-\gamma}\left\{(1-y)^{1-\gamma} \cdot\left(u^{1-\gamma} \cdot \pi_{u}+\beta p \cdot\left(u^{2(1-\gamma)} \cdot \pi_{u}^{2}+(d u)^{1-\gamma} \cdot \pi_{d u}\right)\right)\right. \\
\left.+(1+y)^{1-\gamma} \cdot\left(d^{1-\gamma} \cdot \pi_{d}+\beta p \cdot\left((u d)^{1-\gamma} \cdot \pi_{u d}+d^{2(1-\gamma)} \cdot \pi_{d}^{2}\right)\right)\right\}
\end{array}
$$

Therefore:

$$
U_{0}=\frac{\beta}{1-\gamma} \cdot S_{0}{ }^{1-\gamma}\left\{(1-y)^{1-\gamma} \cdot B+(1+y)^{1-\gamma} \cdot A\right\}
$$

with

$$
\begin{aligned}
& A=d^{1-\gamma} \cdot \pi_{d}+\beta p\left(u d^{1-\gamma} \cdot \pi_{u d}+d^{2(1-\gamma)} \cdot \pi_{d}^{2}\right) \\
& B=u^{1-\gamma} \cdot \pi_{u}+\beta p\left(u^{2(1-\gamma)} \cdot \pi_{u}^{2}+d u^{1-\gamma} \cdot \pi_{d u}\right) .
\end{aligned}
$$

Calculating the derivative of $U_{0}$ with respect to $y$ and setting it equal to zero gives us:

$$
\begin{gathered}
\frac{d U_{0}}{d x}=\frac{\beta \cdot S_{0}{ }^{1-\gamma}}{1-\gamma}\left\{-(1-\gamma) \cdot(1-y)^{-\gamma} \cdot B+(1-\gamma) \cdot(1+y)^{-\gamma} \cdot A\right\}=0 \\
-(1-y)^{-\gamma} \cdot B+(1+y)^{-\gamma} \cdot A=0
\end{gathered}
$$




$$
\begin{gathered}
-(1-y) \cdot B^{\frac{1}{\gamma}}+(1+y) \cdot A^{\frac{1}{\gamma}}=0 \\
y \cdot A^{\frac{1}{\gamma}}+y \cdot B^{\frac{1}{\gamma}}=A^{\frac{1}{\gamma}}-B^{\frac{1}{\gamma}}
\end{gathered}
$$

Solving for the smoothing factor $y$ yields:

$$
y=\frac{A^{\frac{1}{\gamma}}-B^{\frac{1}{\gamma}}}{A^{\frac{1}{\gamma}}+B^{\frac{1}{\gamma}}}
$$

The value $V I_{0}$ of the PLA for the insurer is given by:

$$
\mathrm{VI}_{0}=\frac{\mathrm{N}(1+\mathrm{p}) \mathrm{S}_{0} \cdot\left[\mathrm{q}^{2} \cdot \mathrm{u}^{2}-(1-\mathrm{q})^{2} \cdot \mathrm{d}^{2}\right]}{(1+\mathrm{i})^{2}} \cdot \mathrm{y}
$$

with the risk-neutral probability of an upward jump $q$ and the riskless interest rate $i . S_{0}$ and $(1+p)$ are positive variables. Consequently, the value of the insurer is a linear function of the smoothing parameter $y$ if:

$$
q^{2} \cdot u^{2}>(1-q)^{2} \cdot d^{2} \quad \text { or } \quad q>\frac{d}{u+d}
$$

Replacing $q$ with its definition $((1+i)-d) /(u-d)$ gives us the following result:

$$
\frac{(1+i)-d}{u-d}>\frac{d}{u+d}
$$

We rearrange terms and assume $u>d>0$ :

$$
\begin{gathered}
(1+i) \cdot(u+d)-d(u+d)>d(u-d) \\
(1+i) u>2 d u-(1+i) d \\
\frac{u}{d}>\frac{2 u-(1+i)}{1+i}
\end{gathered}
$$

Since $u>1+i$ by definition, finally we can solve for $d$ :

$$
\frac{(1+i) u}{2 u-(1+i)}>d
$$




\section{Appendix B: Capital Market and Mortality Model}

The portfolio of our life insurance company includes a stock and a bond fund. The stochastic dynamics of the bond fund are modeled using a multi-factor CIR model of the term structure as described in Chen and Scott (1993). In this model, the short rate $r^{C I R}$ is the sum of $K$ independent state variables:

$$
r^{C I R}=\sum_{i=1}^{K} r_{i}^{C I R}
$$

Each of the state variables followings a CIR-type square root diffusion process:

$$
d r_{i}^{C I R}=\left(\mu_{i}^{C I R}-\alpha_{i} \cdot r_{i}^{C I R}\right) d t+\sigma_{i}^{C I R} \sqrt{r_{i}^{C I R}} d W_{i}
$$

where $\alpha_{i}, \mu_{i}^{C I R}$, and $\sigma_{i}^{C I R}$ are positive constants and $r_{i}^{C I R}>0$, if $\mu_{i}^{C I R}>\left(\sigma_{i}^{C I R}\right)^{2} . W_{i}$ are independent Wiener processes.

The term structure of interest rates has an affine structure and is described by:

$$
R(t, \tau)=\sum_{i=1}^{3}-\frac{\log A_{i}(\tau)}{\tau}+\frac{H_{i}(\tau)}{\tau} r_{i, t}^{C l R}
$$

where $R(t, \tau)$ represents the $\tau$-period spot rate at time $t$, and $A_{i}(\tau)$ and $H_{i}(\tau)$ are given by

$$
\begin{gathered}
\mathrm{A}_{\mathrm{i}}(\tau)=\left[\frac{2 \gamma_{i} e^{\left(\alpha_{i}+\lambda_{i}+\gamma_{i}\right) \tau / 2}}{2 \gamma_{i}+\left(\alpha_{i}+\lambda_{i}+\gamma_{i}\right)\left(e^{\gamma_{i} \tau}-1\right)}\right]^{2 \mu_{i}{ }^{C I R} /\left(\sigma_{i}^{C I R}\right)^{2}} \\
\mathrm{H}_{i}(\tau)=\frac{2\left(e^{\gamma_{i} \tau}-1\right)}{\left(\alpha_{i}+\lambda_{i}+\gamma_{i}\right)\left(e^{\gamma_{i} \tau}-1\right)+2 \gamma_{i}} \\
\gamma_{i}=\sqrt{\left(\alpha_{i}+\lambda_{i}\right)^{2}+2\left(\sigma_{i}^{C I R}\right)^{2}} .
\end{gathered}
$$

where the $\lambda_{i}$ are constants.

We assume that the insurer holds a bond fund with target duration $D$ that is re-adjusted at the beginning of each period to maintain that target value. The price $B$ of one unit of the bond fund evolves according to:

$$
B_{t+1}=B_{t} \cdot\left[\frac{(1+R(t, D))^{D}}{(1+R(t+1, D-1))^{D-1}}-R(t, D)\right],
$$

with $R(t, \tau)$ being the spot rates from equation (A3). The bond fund pays annual coupons $C_{t+1}$ given by:

$$
C_{t+1}=B_{t} \cdot R(t, D)
$$

In addition to the bond fund, the insurer invests in stocks, with prices $S_{t}$ evolving according to:

$$
S_{t}=S_{t-1} \cdot e^{r_{t}^{C I R}+r_{t}^{R P}}=S_{t-1} \cdot e^{r_{t}^{C I R}+\mu^{R P}+\sigma^{R P} W_{t}^{2}}
$$


Here, $r_{t}^{C I R}$ is again the short rate, and $r_{t}^{R P}=\mu^{R P}+\sigma^{R P} W_{t}^{2}$ is the stochastic risk premium (net of non-stochastic dividends) with constants $\mu^{R P}$ and $\sigma^{R P}$ and a standard Wiener process $W_{t}^{2}$ uncorrelated to $W_{i, t}^{1}$. Stocks pay an annual dividend $D_{t}$ based on a fixed dividend yield $\mu^{D}$ :

$$
D_{t}=S_{t-1} \cdot\left(e^{\mu^{D}}-1\right)
$$

To calibrate the term structure model, we rely on historical data on US 3-month T-bills rates and US Treasury zero yields with maturities of 1 to 10 years over the period January 1988 to December 2012. ${ }^{27}$ We set $K=3$, as the a 3-factor CIR model provide the best fit to the data when compared to alternative parsimonious multi-factor specifications. Based on this data and model specification, the calibration approach presented in Chen and Scott (1993) produced the following parameter estimates (see Table B1), with $r_{i, 0}^{C I R}$ the initial factor value derived from the current term structure:

Table B1: Estimates of 3-factor CIR Model

\begin{tabular}{|c|c|c|c|c|c|}
\hline$i$ & $\mu_{i}^{C I R}$ & $\alpha_{i}$ & $\sigma_{i}^{C I R}$ & $\lambda_{i}$ & $r_{i, 0}^{C I R}$ \\
\hline 1 & 0.0092 & 0.2576 & 0.0851 & -0.2036 & 0.0000 \\
\hline 2 & 0.0014 & 0.3035 & 0.0708 & -0.5642 & 0.0009 \\
\hline 3 & 0.0122 & 0.3108 & 0.1427 & 0.0655 & 0.0188 \\
\hline
\end{tabular}

Note: Estimates of the 3-factor CIR model based on data provided by

Datastream. Source: Authors' calculation.

Stock price developments and dividend rates are calibrated to the S\&P 500 Price Index and the S\&P 500 Dividend Yield Index over the same period (December 1981 to December 2012). This produces the following parameter estimates: $\mu^{R P}=3.28 \%, \sigma^{R P}=16.5 \%$, and $\mu^{D}=2.6 \%$. The insurer's asset allocation follows a constant mix strategy: the portfolio is rebalanced annually toward the targeted allocation when assets are sold to pay benefits to the annuitants. In case the stock exposure exceeds the target exposure, the insurance company sells a higher percentage of stocks to pay the benefits.

When we use the calibration parameters of the asset model described above, we use the risk and return profiles of the asset model reported in Table B2:

Table B2: Means, Standard Deviations and Correlations of Capital Market Model

\begin{tabular}{|c|c|c|c|c|}
\hline & $V_{t}$ & $C_{t}$ & $S_{t}$ & $D_{t}$ \\
\hline Expectation (\%) & 2.30 & 4.21 & 7.89 & 2.63 \\
\hline Standard Deviation (\%) & 11.67 & 1.66 & 18.10 & - \\
\hline \multicolumn{5}{|l|}{ Correlation } \\
\hline$V_{t}$ & 1 & 0 & 0 & 0 \\
\hline$C_{t}$ & 0.4498 & 1 & 0 & 0 \\
\hline$S_{t}$ & 0.0300 & 0.0865 & 1 & 0 \\
\hline$D_{t}$ & 0 & 0 & 0 & 1 \\
\hline
\end{tabular}

Note: Mean, standard deviation and correlation of bond fund $V_{t}$, cupon $C_{t}$, stocks $S_{t}$, and dividends $D_{t}$. Number of simulations $=10.000$, Source: Authors`calculation.

\footnotetext{
${ }^{27}$ Specifically, we use the following Datastream time series: FRTCM3M, FRTNY01, FRTNY02, FRTNY03, FRTNY04, FRTNY05, FRTNY06, FRTNY07, FRTNY08, FRTNY09, FRTNY10.
} 
Following Cairns, Blake and Dowd (CBD, 2006), the stochastic dynamics of the annuitants' actual mortality rates $q_{x}^{P}:=q(t, x)$ at age $x$ and time $t$ are described by:

$$
\operatorname{logit} q_{x}^{P}=\ln \frac{q_{x, t}}{1-q_{x, t}}=\mathrm{K}_{t}^{(1)}+(x-\bar{x}) \cdot \mathrm{K}_{t}^{(2)}
$$

where $q_{x, t}$ are the single year death probabilities, $\mathrm{K}_{t}^{(1)}$ and $\mathrm{K}_{t}^{(2)}$ are period mortality indexes and $\bar{x}$ is the average age over the considered age range. To estimate future mortality rates, the period mortality indexes component $\mathrm{K}_{t}^{(1)}$ and $\mathrm{K}_{t}^{(2)}$ are forecasted using a bivariate random walk with drift:

$$
\mathrm{K}_{t+1}=\mathrm{K}_{t}+\mu^{C B D}+\Sigma \cdot \varepsilon_{t} .
$$

Here, $\mu^{C B D}$ and $\mathrm{K}_{t}$ are constant vectors, $\Sigma$ is an upper triangular $2 \mathrm{x} 2$ matrix, and $\varepsilon_{t}$ is 2-dimensional standard normal random vector.

We calibrate the CBD model to US mortality data from the Human Mortality Database. ${ }^{28}$ This produces the parameter estimates reported in Table B3:

\begin{tabular}{|c|c|c|c|c|}
\hline$i$ & $\mathrm{~K}_{t}$ & $\mu^{C B D}$ & $\Sigma$ & \\
\hline 1 & -10.9033 & -0.0400 & 0.0719 & 0 \\
\hline 2 & 0.1011 & 0.0004 & -0.0010 & 0.0003 \\
\hline
\end{tabular}

Table B3: Calibration of CBD Mortality Model

Note: Estimated parameters of the CBD mortality model based on US mortality data for the human mortality database. $\mathrm{K}_{\mathrm{t}}$ the period mortality index, $\mu^{C B D}$ estimated mortality, $\Sigma$ correlation matix Source: Authors' calculation.

\footnotetext{
${ }^{28}$ Specifically we use the U.S. Death Rates (Period 1x1), Males and Females, Last modified: 16-Nov-2012, Version MPv5 for the period 1933-2010. See http://www.mortality.org.
} 


\section{References}

Allen, F. and Carletti, E. (2008): Mark-to Market Accounting and Liquidity Pricing. Journal of Accounting and Economics 45: 358-378.

Beyer, A.; Cohen, D.A.; Lys, T. Z. and Walther, B.R. (2010): The Financial Reporting Environment: Review of the Recent Literature. Journal of Accounting and Economics 50: 296-343.

Bleck, A. and Liu, X. (2007): Market Transparency and the Accounting Regime. Journal of Accounting Research 45(2): 229-256.

Brown, J.R.; Mitchell, O. S.; Poterba, J.M. and Warshawsky, M.J. (2001): The Role of Annuity Markets in Financing Retirement. MIT Press: Cambridge.

Cairns, A.; Blake, D. and Dowd, K. (2006): A Two-Factor Model for Stochastic Mortality with Parameter Uncertainty: Theory and Calibration. Journal of Risk and Insurance 73: 687-718.

Chen, R. R. and Scott, L. (1993): Maximum Likelihood Estimation for a Multifactor Equilibrium Model of the Term Structure of Interest Rates. Journal of Fixed Income 3: 14-31.

Comprix, J. and Muller III, K. A. (2011): Pension Plan Accounting Estimates and the Freezing of Defined Benefit Pension Plans. Journal of Accounting and Economics 51: 115-133.

Davidoff, T.; Brown, J.R. and Diamond, P.A. (2005): Annuities and Individual Welfare. American Economic Review 95(5): 1573-1590.

Denuit, M.; Haberman, S. and Renshaw, A. (2011): Longevity-indexed Annuities. North American Actuarial Journal 15(1): 97-111.

Ellul, A.; Jotikasthira, A. C.; Lundblad, C. T. and Wang, Y. (2013): Mark-to-Market Accounting and Systemic Risk: Evidence from the Insurance Industry. Paper prepared for the 58th Panel Meeting of Economic Policy.

Guillen, M.; Jorgensen, P.L. and Nielsen, J.P. (2006): Return Smoothing Mechanisms in Life and Pension Insurance: Path-dependent Contingent Claims. Insurance: Mathematics and Economics 38: 229-252.

Hann, R.N.; Heflin, F. and Subramanayam, K.R. (2007): Fair-value Pension Accounting. Journal of Accounting and Economics 44: 328-358.

Heaton, J.; Lucas, D. and McDonald, R. (2010): Is Mark-to-market Accounting Destabilizing? Analysis and Implications for Policy. Journal of Monetary Economics 57: 64-75.

Herget, R.T.; Freedman, M. J.; McLaughlin, S. M. and Schuering, E. P. (2008): US GAAP for Life Insurers. Second Edition. Society of Actuaries: Schaumburg, III.

Horneff, W.; Maurer, R. and Rogalla, R. (2010): Deferred Annuities and Dynamic Portfolio Choice. Journal of Banking and Finance 34: 2652-2664.

Hull, J. C. (2000): Options, Futures, and Other Derivatives. 4th Ed. Prentice Hall: Upper Saddle River.

Inkmann, J.; Lopez, P. and Michaelides, A. (2011): How Deep is the Annuity Market Participation Puzzle? Review of Financial Studies 24(1): 279-319.

Jorgensen, P.L. (2004): On Accounting Standards and Fair Valuation of Life Insurance and Pension Liabilities. Scandinavian Actuarial Journal 104(5): 372-394.

Koijen, R.S and Yogo, M. (2013): The Cost of Financial Frictions for Life Insurers. Chicago Booth Research Paper No. 12-30. Available at SSRN: http://ssrn.com/abstract=2031993.

Laux, C. and Leuz, C. (2009): The Crisis of Fair-value Accounting: Making Sense of the Recent Debate. Accounting, Organizations and Society 34: 826-834.

Laux, C., and Leuz, C. (2010): Did Fair-value Accounting Contribute to the Financial Crisis? Journal of Economic Perspectives 24: 93-118.

Lombardi, L. J. (2009): Valuation of Life Insurance Liabilities. 4 ed. ACTEX Publication. Winsted, CT.

Maurer, R.; Mitchell, O.S.; Rogalla, R. and Kartashov, V. (2013): Lifecycle Portfolio Choice with Systematic Longevity Risk and Variable Investment-linked Deferred Annuities. Journal of Risk and Insurance 80(3): 649-676.

Maurer, R.; Rogalla, R. and Siegelin, I. (2013): Participating Payout Life Annuities: Lessons from Germany. ASTIN Bulletin 43: 159-187.

Milevsky, M. and Young, V. (2007): Annuitization and asset allocation. Journal of Economic Dynamics and Control 31, 3138-3177. 
Novy-Marx, R. and Rauh, J.D. (2011): Public Pension Promises: How Big Are They and What Are They Worth? Journal of Finance 66(4): 1207-1245.

Piggott, J.; Valdez, E. A. and Detzel, B. (2005): The Simple Analytics of a Pooled Annuity Fund. Journal of Risk and Insurance 72: 497-520.

Richter, A. and Weber, F. (2011): Mortality-Indexed Annuities: Avoiding Unwanted Risk. North American Actuarial Journal 15: 212-236.

Sapra, H. (2008): Do Accounting Measurement Regimes Matter? A Discussion of Mark-to-Market Accounting and Liquidity Pricing. Journal of Accounting and Economics 45: 379-387.

Society of Actuaries (2013): Observations on Input and Output Smoothing Methods. SOA: Schaumburg, II.

Steverman, B. (2012): “Mark Iwry: Bringing Annuities to 401(k)s.” BloombergBusinessWeek.com. April 17. http://www.businessweek.com/news/2012-04-17/mark-iwry-bringing-annuities-to401-k-s.

TIAA-CREF (2011): Audited Statutory - Basis Financial Statements. As of December 31, 2011 and 2010, and for the three years ending December 31, 2011. New York. 
Figure 1: Stylized Model of Participating Life Annuity with Payout Smoothing

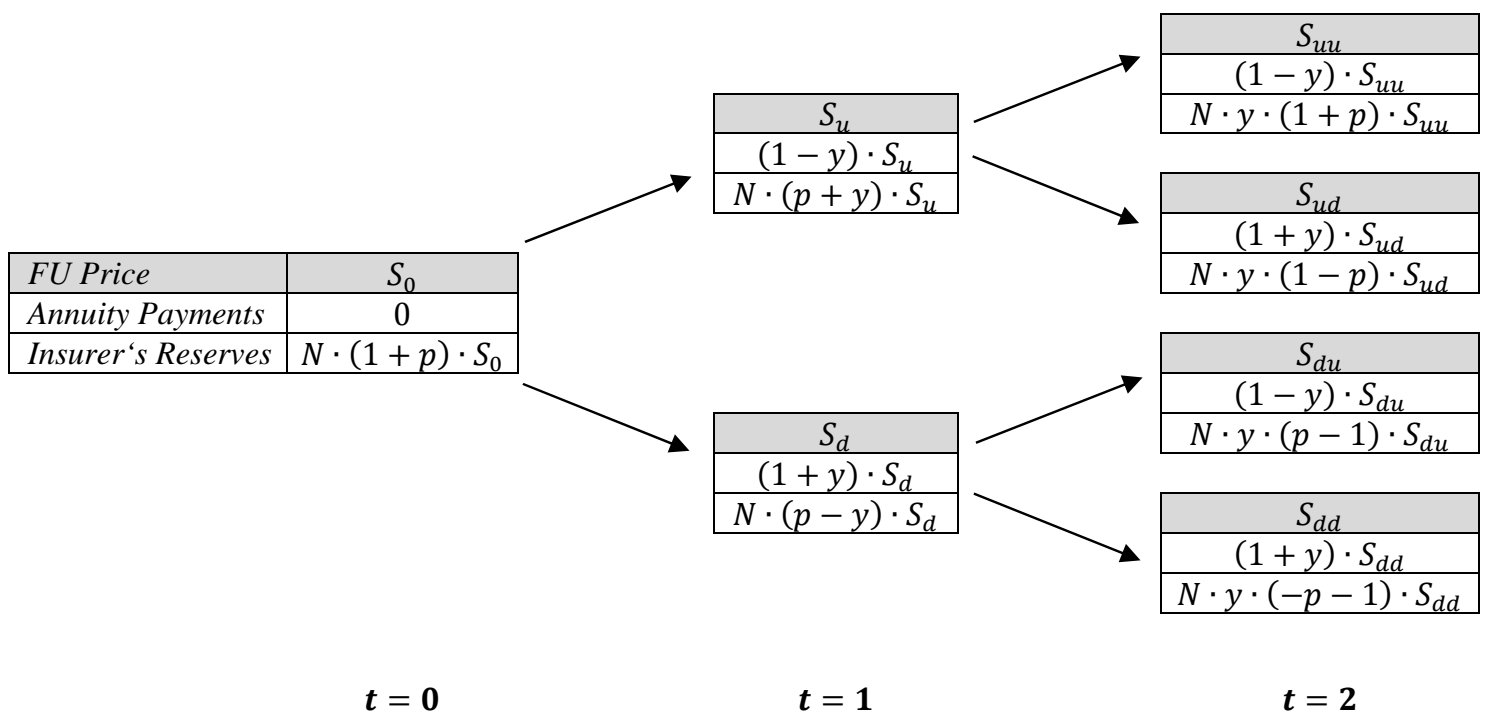

Notes: Evolution of Fund Unit (FU) prices, annuity benefits, and insurer reserves over two periods if smoothing is applied. The number of individuals, $N$, the smoothing factor $y$, the two-year survival probability $p$, the initial price of the FU $S_{0}$, and the FU prices in the following periods $S_{u}, \mathrm{~S}_{\mathrm{d}}, \mathrm{S}_{\mathrm{uu}}, \mathrm{S}_{\mathrm{ud}}, \mathrm{S}_{\mathrm{du}}$ and $S_{d d}$, with $S_{d u}=d \cdot u \cdot S_{0}$. Source: Authors' illustration; see text.

Figure 2: Threshold Subjective Probability of Downward Jumps Necessary to Value Smoothing

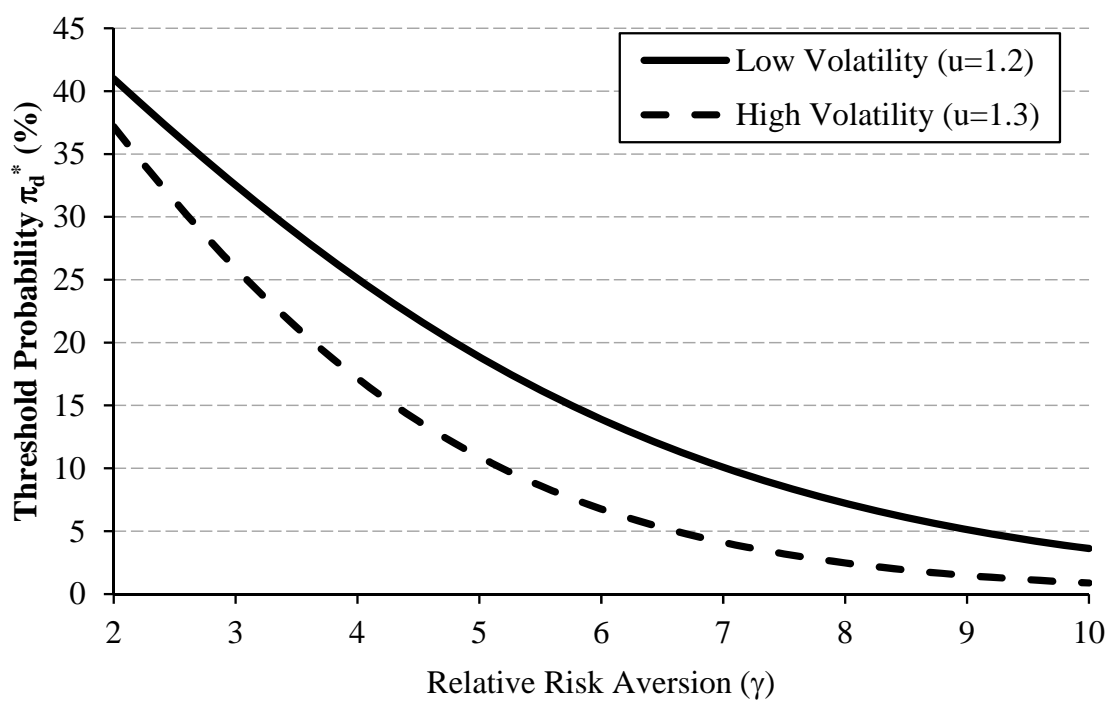

Notes: Participating Life Annuity (PLA) policyholder's subjective probability $\pi_{d}^{*}$ for a capital market downturn beyond which PLA payout smoothing is utility increasing for alternative levels of relative risk aversion $(\gamma)$. Calibration: time preference rate: $\beta=0.96,2$-period survival probability: $p=0.8$. Capital markets: Fund unit (FU) price may increase (decrease) by a proportional factor of $u(d=1 / u)$. Source: Authors' calculations; see text. 
Figure 3: Effect of Asset Allocation versus Valuation Method on PLA Policyholder Utility

\section{Panel A: Accounting Smoothing}

A1: FMV vs. HCV

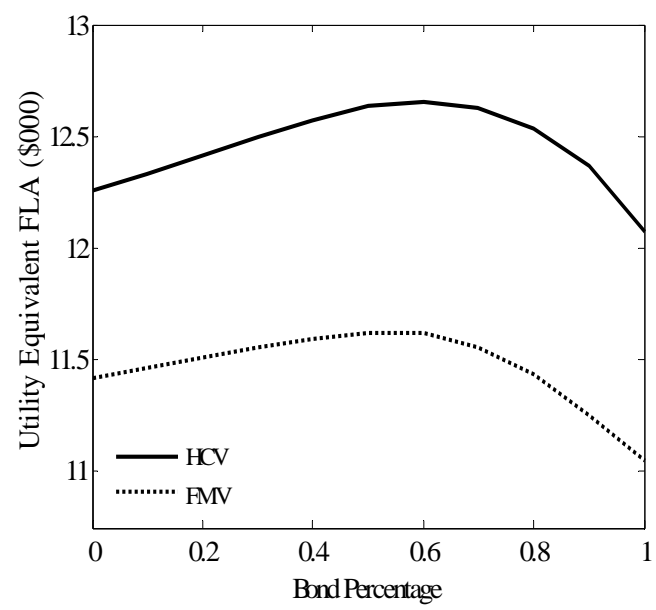

A2: Asset Allocation vs. Valuation Method

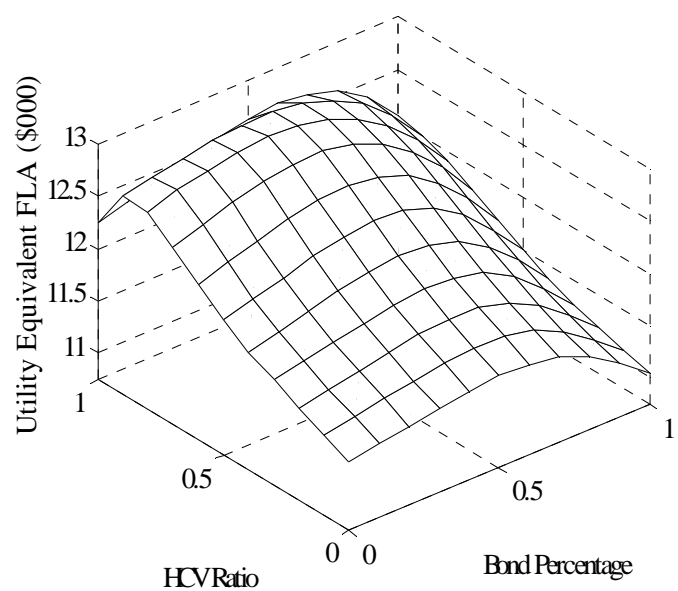

Panel B: Accounting and Actuarial Smoothing

B1: FMV vs. HCV

B2: Asset Allocation vs. Valuation Method

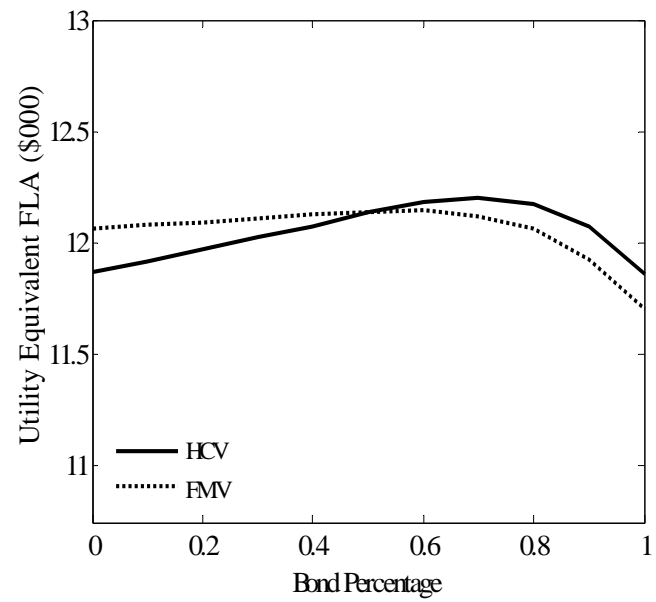

Notes: Utility equivalent fixed life annuity (FLA; in \$000) that generates the same utility as a Participating Lifetime Annuity (PLA) with a guaranteed initial lifelong annual benefits of $\$ 10,000$ for alternative scenarios based on a time-additive CRRA utility function. $\mathrm{HCV}=$ Historical Cost Valuation, FMV = Fair Market Valuation. Calibration accounting smoothing, male age 65 in 2013; initial guaranteed PLA benefits: $\$ 10,000$; time preference: $\beta=0.96$; relative risk aversion: $\gamma=5$; GIR: $3 \%$; mortality table: “Annuity 2000" (PLA present value \$163,399); bonds fund duration: 10 years; surplus allocation to annuitant: $90 \%$; equity capital endowment: $4 \%$; solvency limit $4 \%$; initial contingency reserve: $0 \%$; target contingency reserve $0 \%$. Calibration accounting and actuarial smoothing, initial contingency reserve: $5 \%$; target contingency reserve $10 \%$. Source: Authors' calculations; see text. 
Figure 4: Effect of Asset Allocation versus Valuation Method on Insurer Profitability and Stability for a PLA Product

Panel A: Accounting Smoothing

A1: FMV vs. HCV

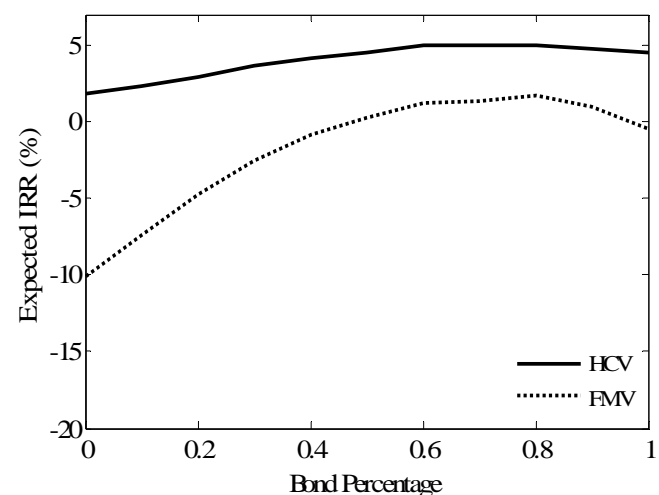

B1: FMV vs. HCV

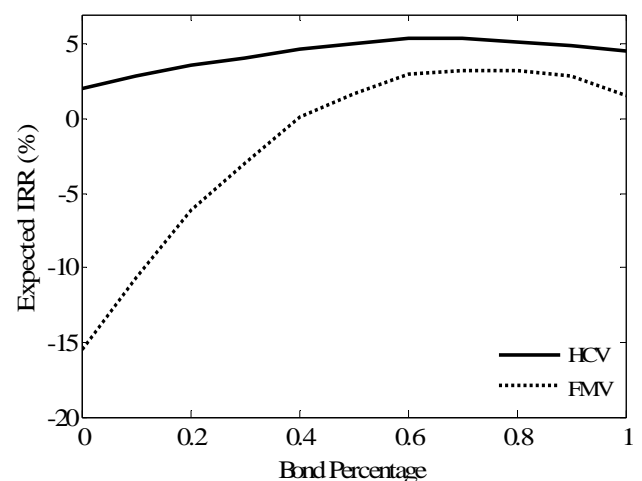

A2: Asset Allocation vs. Valuation Method

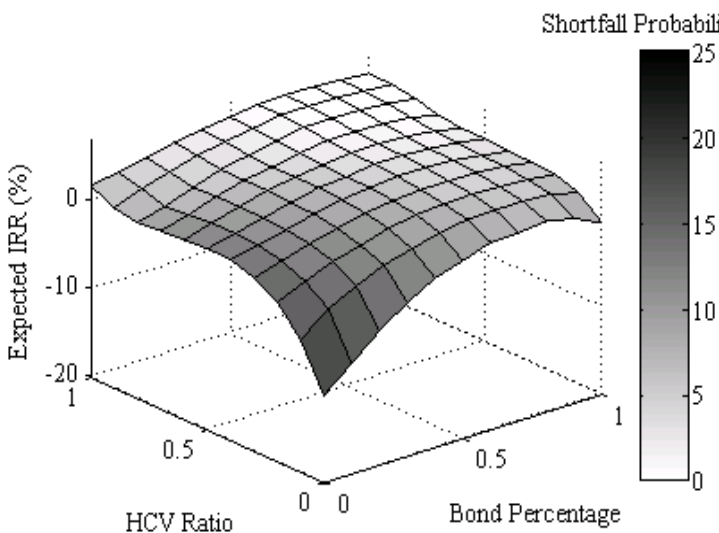

Panel B: Accounting and Actuarial Smoothing

B2: Asset Allocation vs. Valuation Method

Shortfall Probability (\%)

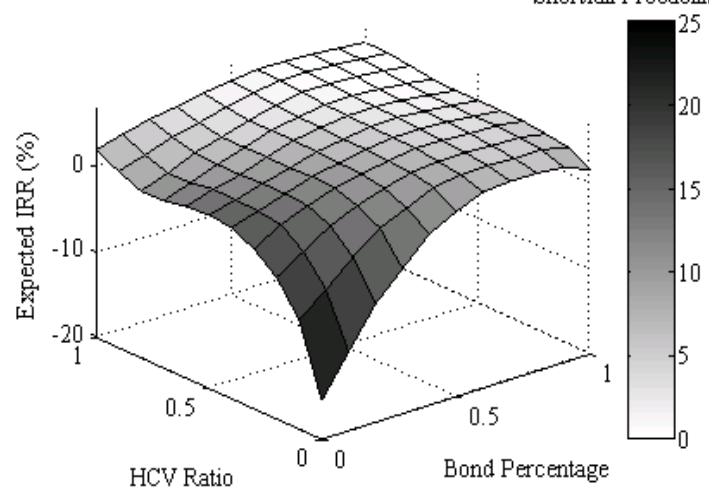

A3: Shortfall Probability of Corner Cases over Time

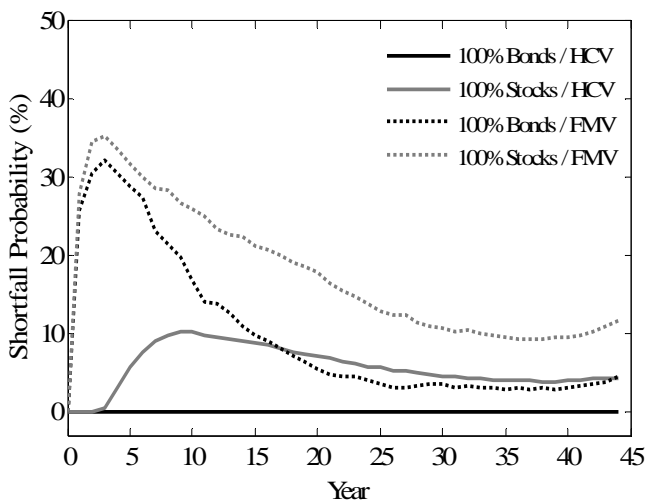

B3: Shortfall Probability of Corner Cases over Time

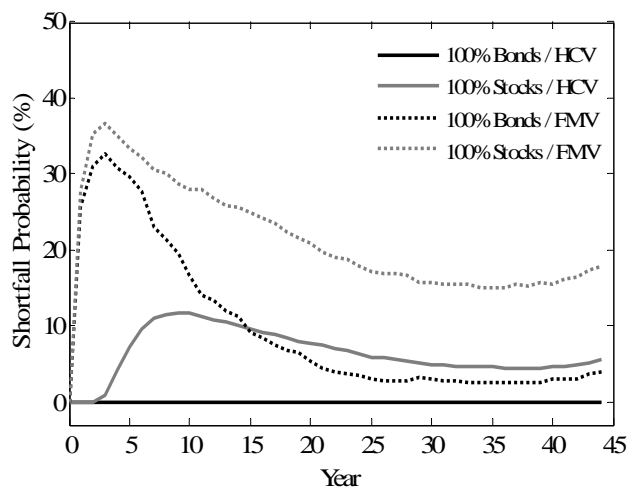

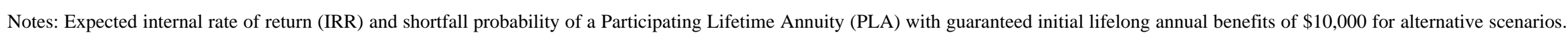
HCV = historical cost valuation, FMV = fair market valuation. Calibration accounting smoothing, male age 65 in 2013; initial guaranteed PLA benefits: $\$ 10,000$; time preference: $\beta=0.96$; relative risk aversion: $\gamma=5$; GIR: 3\%; mortality table: “Annuity 2000” (PLA present value \$163,399); bonds fund duration: 10 years; surplus allocation to annuitant: 90\%; equity capital endowment: 4\%; solvency limit $4 \%$; initial contingency reserve: $0 \%$; target contingency reserve $0 \%$. Calibration asset and actuarial smoothing, initial contingency reserve: $5 \%$; target contingency reserve $10 \%$. Source: Authors`calculations. 
Figure 5: Effect of Alternative Valuation Methods on PLA Policyholder and Insurer Outcomes

\section{Panel A: Accounting Smoothing}

A1: Annuitants' Perspective

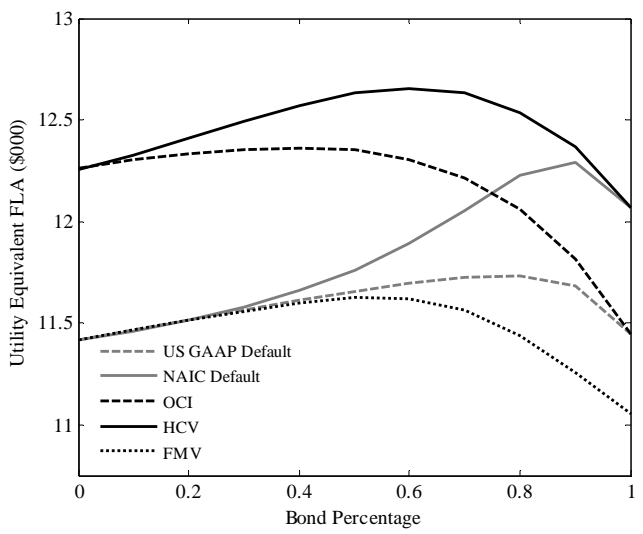

A2: Insurers' Perspective

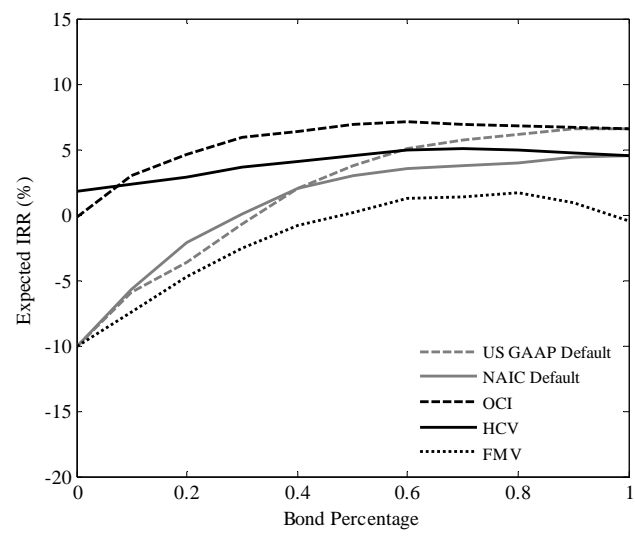

Panel B: Accounting and Actuarial Smoothing

B1: Annuitants' Perspective

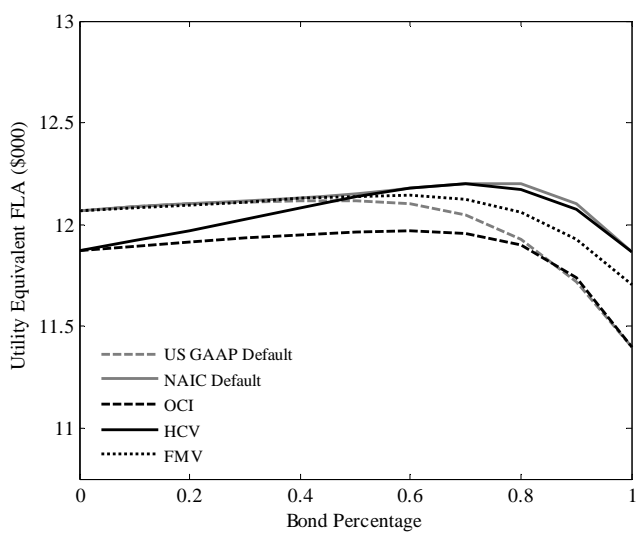

B2: Insurers' Perspective

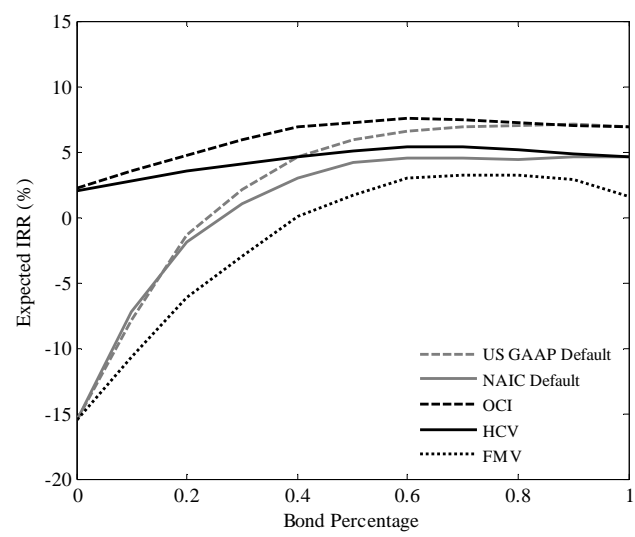

Notes: Figure A1 and B1 show the utility equivalent fixed life annuity (in \$000) that generates the same utility as a Participating Lifetime Annuity (PLA) with a guaranteed initial lifelong annual benefits of $\$ 10,000$ based on a time-additive CRRA utility function for alternative valuation scenarios. Figure A2 and B2 show the expected internal rate of return (IRR). OCI = other comprehensive income valuation, HCV = historical cost valuation, FMV = fair market valuation, US GAAP Default = bond valuation OCI and stock valuation FMV, NAIC Default = bond valuation HCV and stock valuation FMV. Calibration accounting smoothing, male age 65 in 2013; initial guaranteed PLA benefits: \$10,000; time preference: $\beta=0.96$; relative risk aversion: $\gamma=5$; GIR: 3\%; mortality table: “Annuity 2000” (PLA present value $\$ 163,399$ ); bonds fund duration: 10 years; surplus allocation to annuitant: $90 \%$; equity capital endowment: $4 \%$; solvency limit $4 \%$; initial contingency reserve: $0 \%$; target contingency reserve $0 \%$. Calibration asset and actuarial smoothing, initial contingency reserve: 5\%; target contingency reserve $10 \%$. Source: Authors`calculations; see text. 


\section{Figure 6: Impact of Surplus Sharing and Actuarial Smoothing on Key Outcomes}

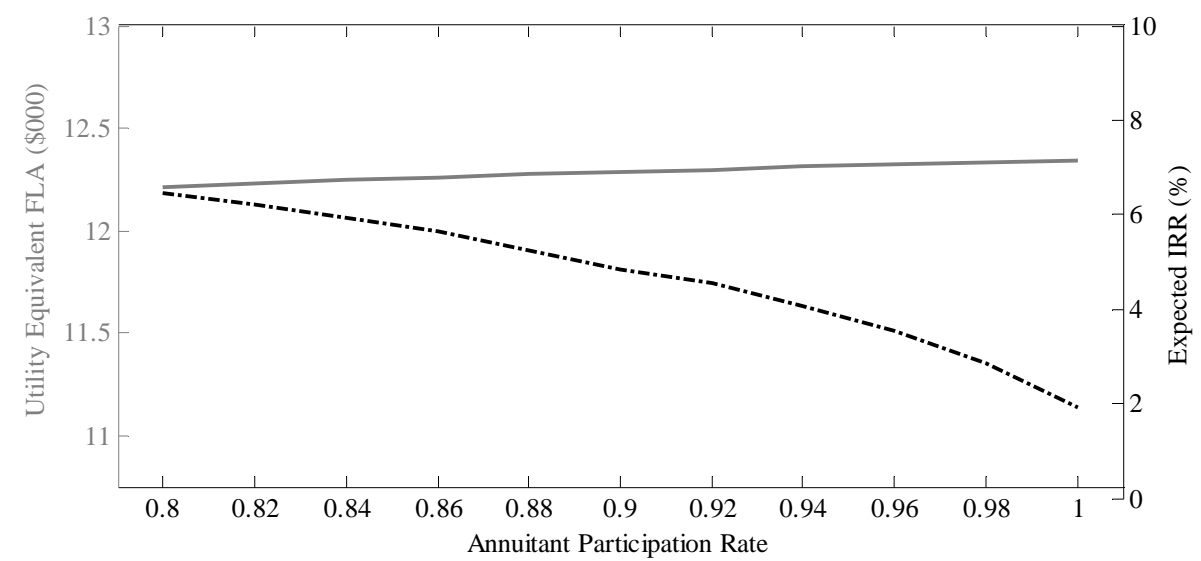

Notes: Optimal utility equivalent fixed life annuity (FLA; in \$000) that generates the same utility as a Participating Lifetime Annuity (PLA) with a guaranteed initial lifelong annual benefits of $\$ 10,000$ based on a time-additive CRRA utility function, corresponding internal rate of return for alternative annuitant participation rates. HCV $=$ historical cost valuation. Calibration, male age 65 in 2013; initial guaranteed PLA benefits: $\$ 10,000$; time preference: $\beta=0.96$; relative risk aversion: $\gamma=5$; GIR: 3\%; mortality table: “Annuity 2000” (PLA present value \$163,399); bonds fund duration: 10 years; equity capital endowment: $4 \%$; solvency limit $4 \%$; initial contingency reserve: $5 \%$; target contingency reserve $10 \%$. Source: Authors`calculations; see text. 
Table 1: Stylized Two Period Model of Participating Life Annuity(PLA) with Smoothing

\begin{tabular}{|c|c|c|c|c|c|c|}
\hline & \multicolumn{2}{|c|}{$\begin{array}{c}\text { Annuitants' Optimal } \\
\text { Smoothing Factor } y \\
\text { (in \%) }\end{array}$} & \multicolumn{2}{|c|}{$\begin{array}{l}\text { Welfare Gains from } \\
\text { Optimal Smoothing } \\
\text { (in \%) }\end{array}$} & \multicolumn{2}{|c|}{$\begin{array}{l}\text { Insurers' Gains from } \\
\text { Optimal Smoothing } \\
\text { (in \%) }\end{array}$} \\
\hline & $\pi_{d}=0.2$ & $\pi_{d}=0.5$ & $\pi_{d}=0.2$ & $\pi_{d}=0.5$ & $\pi_{d}=0.2$ & $\pi_{d}=0.5$ \\
\hline \multicolumn{7}{|c|}{ Low Volatility Capital Market Scenario $(u=1.2)$} \\
\hline$\gamma=2$ & 0 & 9.1 & 0 & 0.8 & 0 & 0.8 \\
\hline$\gamma=5$ & 0.7 & 14.5 & 0.01 & 4.9 & 0.1 & 1.3 \\
\hline$\gamma=10$ & 11.9 & 16.3 & 3.6 & 9.9 & 1.1 & 1.5 \\
\hline \multicolumn{7}{|c|}{ High Volatility Capital Market Scenario $(u=1.3)$} \\
\hline$\gamma=2$ & 0 & 13.0 & 0 & 1.7 & 0 & 1.7 \\
\hline$\gamma=5$ & 13.1 & 20.7 & 0.3 & 9.5 & 1.7 & 2.7 \\
\hline$\gamma=10$ & 18.1 & 23.2 & 10.0 & 16.8 & 2.4 & 3.0 \\
\hline
\end{tabular}


Table 2: Utility-Maximizing Asset Allocation and Valuation Methods for PLA Policyholder Having Alternative Levels of Risk Aversion

\begin{tabular}{|c|c|c|c|c|c|c|}
\hline \multirow[b]{2}{*}{ Relative Risk Aversion } & \multicolumn{3}{|c|}{ Accounting Smoothing } & \multicolumn{3}{|c|}{ Accounting and Actuarial Smoothing } \\
\hline & $\begin{array}{c}\text { Bond } \\
\text { Percentage }\end{array}$ & $\begin{array}{l}\text { HCV } \\
\text { Ratio }\end{array}$ & $\begin{array}{l}\text { Optimal Utility } \\
\text { Equivalent FLA }\end{array}$ & $\begin{array}{c}\text { Bond } \\
\text { Percentage }\end{array}$ & $\begin{array}{l}\text { HCV } \\
\text { Ratio }\end{array}$ & $\begin{array}{l}\text { Optimal Utility } \\
\text { Equivalent FLA }\end{array}$ \\
\hline Low $/ \gamma=2$ & 0 & 80 & 15,533 & 10 & 70 & 14,159 \\
\hline Medium / $\gamma=5$ & 40 & 80 & 12,881 & 60 & 70 & 12,283 \\
\hline High $/ \gamma=10$ & 80 & 100 & 11,783 & 80 & 70 & 11,469 \\
\hline
\end{tabular}

Notes: Optimal utility equivalent fixed life annuity (FLA; in \$) with respective asset allocation percentage and book value ratio for alternative calibrations of the time-additive CRRA utility function. Calibration accounting smoothing, male age 65 in 2013; initial guaranteed Participating Lifetime Annuity (PLA) benefits: $\$ 10,000$; time preference: $\beta=0.96$; relative risk aversion: low $(\gamma=2)$, medium $(\gamma=5)$, high $(\gamma=10)$; GIR: 3\%; mortality table: “Annuity 2000” (PLA present value $\$ 163,399)$; bonds fund duration: 10 years; surplus allocation to annuitant: $90 \%$; equity capital endowment: $4 \%$; solvency limit $4 \%$; initial contingency reserve: $0 \%$; target contingency reserve: $0 \%$. Calibration asset and actuarial smoothing, initial contingency reserve: $5 \%$; target contingency reserve $10 \%$. Source: Authors`calculations; see text.

Table 3: Impacts of Optimal Combination of Asset Allocation and Valuation Method on Internal Rates of Return and Shortfall Probabilities, PLA Policyholder Having Alternative Levels of Risk Aversion

\begin{tabular}{|c|c|c|c|c|c|}
\hline & $\begin{array}{l}\text { Relative Risk } \\
\text { Aversion }\end{array}$ & $\begin{array}{c}\text { Bond } \\
\text { Percentage }\end{array}$ & $\begin{array}{l}\mathrm{HCV} \\
\text { Ratio }\end{array}$ & $\begin{array}{l}E(I R R) \\
(\text { in \%) }\end{array}$ & $\begin{array}{c}\text { Shortfall } \\
\text { Probability (in \%) }\end{array}$ \\
\hline \multirow[t]{3}{*}{ Accounting Smoothing } & Low $/ \gamma=2$ & 0 & 80 & 6.20 & 6.96 \\
\hline & Medium / $\gamma=5$ & 40 & 80 & 3.61 & 1.58 \\
\hline & High $/ \gamma=10$ & 80 & 100 & 4.97 & 0.00 \\
\hline \multirow[t]{3}{*}{ Asset and Actuarial Smoothing } & Low $/ \gamma=2$ & 10 & 70 & 6.60 & 8.24 \\
\hline & Medium / $\gamma=5$ & 60 & 70 & 4.85 & 0.75 \\
\hline & High $/ \gamma=10$ & 80 & 70 & 4.67 & 0.15 \\
\hline
\end{tabular}

Notes: Expectation of internal rate of return and shortfall probability in percent for the optimal utility-equivalent fixed life annuity for alternative scenarios. Calibration accounting smoothing, male age 65 in 2013; initial guaranteed Participating Lifetime Annuity (PLA) benefits: $\$ 10,000$; time preference: $\beta=0.96$; relative risk aversion: low $(\gamma=2)$, medium $(\gamma=5)$, high $(\gamma=10)$; GIR: 3\%; mortality table: “Annuity 2000” (PLA present value \$163,399); bond fund duration: 10 years; surplus allocation to annuitant: $90 \%$; equity capital endowment: $4 \%$; solvency limit $4 \%$; initial contingency reserve: $5 \%$; target contingency reserve: $0 \%$. Calibration asset and actuarial smoothing, initial contingency reserve: $5 \%$; target contingency reserve $10 \%$. Source: Authors`calculations; see text. 